\title{
On the Mechanism of Superelasticity in Gum metal (Ti-36Nb- 2Ta-3Zr-0.30)
}

\author{
R. J. Talling ${ }^{1}$, R.J. Dashwood ${ }^{2}$, M. Jackson ${ }^{3}$ and D. Dye ${ }^{1}$ \\ ${ }^{1}$ Department of Materials, Imperial College, South Kensington, London SW7 2AZ, UK. \\ ${ }^{2}$ Warwick Manufacturing Group, Warwick University, Coventry CV4 7AL, UK \\ ${ }^{3}$ Department of Engineering Materials, University of Sheffield, Sheffield S1 3JD UK.
}

The deformation mechanisms of the recently developed multifunctional $\beta$ titanium alloy, Gum metal were investigated with the aid of in-situ synchrotron X-ray diffraction (SXRD) and transmission electron microscopy (TEM).

SXRD results showed that Gum metal undergoes a reversible stress-induced martensitic $(\alpha ")$ phase transformation. It is suggested that oxygen may increase the resistance to shear by increasing $C^{\prime}$ and limiting the extent of $\alpha$ " growth in Gum metal. Prior deformation was found to aid the formation of $\alpha$ " by providing nuclei, such as twins and stress-induced $\omega$ plates. The formation of $\{112\}<111>$ deformation twins and stress-induced $\omega$ plates, both observed in TEM, are believed to be a result of a low $G_{111}$ in this alloy. Features similar to the giant faults seen previously were observed in TEM, their formation is believed to be a result of $\{112\}<111>$ shear.

Keywords: Gum metal, martensitic phase transformation, titanium alloys, synchrotron radiation, transmission electron microscopy.

\section{Introduction}

The recently developed multifunctional $\beta$ titanium alloy, Gum metal (Ti-36Nb-2Ta-3Zr-0.3O) possesses low elastic modulus ( $\sim 60 \mathrm{GPa}$ ), high strength ( $>1 \mathrm{GPa})$, high yield strain $(\sim 2.5 \%)$ and high ductility $(>10 \%)$ at room temperature $[1,2]$. This alloy also possesses the invar and elinvar properties and is highly cold workable. It is reported that the observed 'superproperties' in Gum metal are 
achieved when the following electronic 'magic numbers' are simultaneously satisfied: (i) a compositional average valence electron number (e/a) of $\sim 4.24$, (ii) a bond order (Bo) of $\sim 2.87$ and, (iii) a d-electron orbital energy (Md) of $\sim 2.45 \mathrm{eV}$. The alloy requires cold working and $>0.7$ at.\% oxygen to achieve these properties. Gum metal is a candidate material in a range of applications, including automotive components, implants, sporting goods and space instruments.

It is claimed that Gum metal plastically deforms without the aid of dislocation glide [1-6] and it is suggested that the ideal shear strength of this alloy is comparable with the actual strength. This implies that plastic deformation can occur by ideal shear without any dislocation activity, which explains the existence of the 'giant faults' observed in TEM whose orientation does not correspond to any $b c c$ slip or twin systems $[1,3,4]$. Since the ideal strength can be estimated from the single crystal elastic constants (SECs), $C_{\mathrm{ij}}$, [7] these are considered to be key to explaining the deformation mechanisms and hence the super properties of Gum metal, Equation 1. The SECs of a variety of binary titanium alloys have been calculated from first principles on the basis of the ultra-soft pseudopotential method with a generalised approximation to density function theory [8]. These calculations indicate that the shear modulus, $C^{\prime}=\left(C_{11}-C_{12}\right) / 2$, approaches zero when the average $e / a$ value is around 4.24 in Ti-X binary alloys. It is suggested that this is attained in Gum metal, whose e/a is 4.24. The ideal shear strength is given by [3]:

$$
\tau_{\max } \approx 0.11 G_{111} \approx 0.11 \times \frac{3 C_{44}\left(C_{11}-C_{12}\right)}{\left(C_{11}-C_{12}\right)+4 C_{44}}
$$

where $\mathrm{G}_{111}$ is the shear modulus along $<111>$ on $\{011\},\{112\}$ or $\{123\}$.

The deformation of Gum metal after $90 \%$ cold work shows non-linear behaviour in the elastic regime, which was previously thought not to be due to a stress-induced phase transformation $[1,9]$. However, recently work has shown that Gum metal does undergo a stress-induced reversible phase transformation, during tension, using in-situ synchrotron X-ray diffraction (SXRD) [10]. Furthermore dislocations have been observed in TEM in cold worked specimens [11]. The stress-induced phase transformation was observed in specimens produced by different processing routes, with differing chemical compositions. In addition, it has been shown that $\left(C_{11}-C_{12}\right)$ is $>32 \mathrm{GPa}$ in Gum metal, 
implying that $\tau_{\max }$ is $>2$ GPa $[10,11]$. Taking this into account, along with the data in Table $1[10,12-$ 21], it appears that in $b c c$ alloys with low ideal shear stresses, the lattice is fundamentally unstable and will therefore undergo a stress-induced phase transformation, before deformation can proceed via ideal shear. Most alloys in Table 1 have ideal shear stresses lower than that of Gum metal, but are known to deform via a stress-induced martensitic phase transformation.

The aim of this work is to identify the stress-induced phase transformation in Gum metal and to develop an understanding about the significance of this transformation on the observed deformation mechanisms and mechanical behaviour. The deformation mechanisms are characterised using in-situ SXRD and complemented with transmission electron microscopy (TEM). The effect of chemical composition, prior deformation and processing route on the deformation mechanisms of Gum metal are also investigated.

\section{Experimental Methods}

\subsection{Manufacturing Process}

The first alloy was obtained by mixing of pure elemental powders (EP). The mixed powder was compacted by cold isostatic pressing at a pressure of $392 \mathrm{MPa}$ and then sintered at $1300^{\circ} \mathrm{C}$ for 16 hours in a vacuum of $10^{-4} \mathrm{~Pa}$ and furnace cooled. The sintered billet was hot forged at $1150^{\circ} \mathrm{C}$ and subsequently hot rolled at $800^{\circ} \mathrm{C}$ to $16 \mathrm{~mm}$ diameter bar. The surface oxide was mechanically removed prior to a solution heat treatment of $900^{\circ} \mathrm{C}$ for 30 mins. Cold work was performed by: (i) rolling a $10 \mathrm{~mm}$ thick cross section of the bar to $1 \mathrm{~mm}$ thickness; (ii) swaging of the $16 \mathrm{~mm}$ diameter bar to $4 \mathrm{~mm}$ diameter bar followed by cold rolling to $1 \mathrm{~mm}$ sheet. This produced three specimen conditions, designated EP0.0, EP0.9 and EP3.5 respectively (where the suffix denotes the amount of cold work).

The second specimen condition was also obtained by a powder metallurgy route. Two batches of plasma sprayed powder were hot isostatically pressed (HIPed) at $140 \mathrm{MPa}$ and $920^{\circ} \mathrm{C}$ in a mild steel can. The HIPed blocks were then solution treated at $1000^{\circ} \mathrm{C}$ for 30 mins and water quenched. One billet was cold rolled to a strain of 0.9 ( $\mathrm{PH} 0.9)$, while a second billet was left in the solution 
treated and quenched condition (PH0.0). In both cases the steel can was removed prior to mechanical testing.

The final processing method exploited ingot metallurgy (IM). An alloy was plasma melted as a $1.2 \mathrm{~kg}$ button from compacted elemental raw materials. Melting was carried out in a water-cooled copper hearth inside a furnace. The furnace was evacuated to $<3 \times 10^{-2} \mathrm{mBar}$ and backfilled with high purity argon. A helium plasma torch of approximately $50 \mathrm{~kW}$ was then used to melt the compact into the hearth. The button was allowed to cool and then the furnace was evacuated and brought up to atmosphere. The button was turned upside down and the whole process of evacuation, backfill, melt, cool and turn-over was repeated three times. A $60 \mathrm{~mm}$ diameter billet was machined from the button and solution treated at $850^{\circ} \mathrm{C}$ for 60 mins. The billet was then coated with Deltatglaze ${ }^{\mathrm{TM}} 3418$ (Acheson, MI, USA) glass lubricant and placed in a steel can with a welded lid. The canned billet was then heat treated at $975^{\circ} \mathrm{C}$ for 105 mins prior to extrusion to $12 \mathrm{~mm}$ rod (IM0.0). The steel can was then machined away. The chemical compositions, 'magic numbers' and $\mathrm{Mo}_{\mathrm{eq}}[14]$ of all specimens are presented in .

In addition to the specimens listed above, some Ti-29Nb-13Ta-4.6Zr sheet was acquired. This alloy was prepared by levitation melting and vacuum arc remelting of raw materials of pure $\mathrm{Ti}, \mathrm{Nb}$, $\mathrm{Ta}$ and $\mathrm{Zr}$, to form an ingot, followed by hot forging at $900^{\circ} \mathrm{C}$ in air. Solution treatment was then performed at $790^{\circ} \mathrm{C}$ for 1 hour, followed by water quenching. In order to compare the extruded microstructure of Gum metal, a near $\beta$ alloy, Ti-5Mo-5Al-5V-3Cr was extruded in the $\beta$ condition, with an extrusion ration of 10:1. Prior to extrusion this material was solution treated at $980^{\circ} \mathrm{C}$ for 1 hour.

\section{2. in-situ SXRD}

Dog-bone shaped specimens with a gauge length of $10 \mathrm{~mm}$ and cross sectional area of 1.75 $\mathrm{mm}^{2}$ were machined from the six Gum metal specimen conditions and mechanically polished to 800 grit. The tensile axis of the worked specimens (PH0.9, EP0.9, EP3.5 and IM0.0) was parallel to the specimen rolling direction or the extrusion direction. Loading tests were performed on a FaME38 
Electro-thermomechanical tester (ETMT) at ID15B at the European Synchrotron Radiation Facility (ESRF), Grenoble, France, using an X-ray energy of $88 \mathrm{KeV}(\lambda=0.1415 \AA)$ and an incident beam size of $0.5 \times 0.5 \mathrm{~mm}$. A Pixium detector at a sample to detector distance of $648 \mathrm{~mm}$ was used to sample the diffraction rings. Sampling times were $\sim 0.4 \mathrm{~s}$. A schematic of the experimental setup is shown in Figure 1. All specimens were deformed at an initial strain rate of $5 \times 10^{-4} \mathrm{~s}^{-1}$. X-ray diffraction rings were segmented and intensity $-d_{\mathrm{hkl}}$ diffraction profiles obtained from a $10^{\circ}$ region from grains with plane normals parallel to the loading direction using the software programme FIT2D [22, 23]. Loading-unloading tensile tests were carried out using the same machine and sample geometry. The crosshead displacement was stopped at nominal strains of $2 \%, 4 \%$ and $6 \%$, then the load was released at $40 \mathrm{~N} / \mathrm{s}$. Finally, the crosshead was stopped at a strain of $8 \%$ and then the load was released. Strain to failure tests were also performed on all specimens, using the same strain rate.

The Ti-29Nb-13Ta-4.6Zr alloy was also strained in-situ under the same conditions, using $\sim 1.75$ x 1.00 x 40 mm 'matchstick' specimens.

\subsection{Microstructural Observation and Texture}

Specimens for light microscopy were prepared by mechanical polishing using $10 \% \mathrm{H}_{2} \mathrm{O}_{2}$ in $0.25 \mu \mathrm{m}$ colloidal silica, then etching in a solution of 8 vol. $\% \mathrm{HF}$ and $15 \mathrm{vol} . \% \mathrm{HNO}_{3}$. For TEM, specimens were thinned using twin jet electropolishing in a solution of $8 \% \mathrm{H}_{2} \mathrm{SO}_{4}$ in methanol at $40^{\circ} \mathrm{C}$ and 20 volts. The microstructure of the TEM foil was examined using a Jeol 2000FX TEM operating at $200 \mathrm{kV}$.

Texture measurements were performed on a Philips X'pert MRD machine. Pole Figures were constructed using the program popLA [24]. The texture of EP0.0 and PH0.0 was assumed to be random. 


\section{Results}

\subsection{Characterisation}

Figure 2 shows optical micrographs of all the specimens. The EP0.0 and PH0.0 (Figures 2(a) and 2(d) respectively) specimens exhibit an equiaxed grain structure with an average grain size of approximately $150 \mu \mathrm{m}$. There is evidence in Figure 2(d) that some recrystallisation has occurred in the PH0.0 specimen during the post PH solution heat treatment. The application of $90 \%$ cold work, Figures 2(b) and 2(e), produces a microstructure of elongated grains, which contain features traversing across the grains. Similar features have been observed elsewhere [3] and are believed to be 'giant faults', characteristic of the deformation of Gum metal. With further cold work, the grains become massively elongated, Figure 2(c). The microstructure in the transverse section of the IM0.0 specimen, Figure 2(f) consists of heavily sheared grains, similar to that obtained by swaging $[1,2]$, and that obtained by extrusion of near beta titanium alloy, Ti-5Mo-5Al-5V-3Cr, Figure 3 . The worked structures of Gum metal had previously been thought to be unique to this material and governed by its design magic numbers. Figure 3 shows that similar structures are observed in other titanium alloys, and in addition the 'marble-like' 90\% swaged microstructure of Gum metal [1,2] has been seen in other materials [25]. However, it should be acknowledged that the origin of the filamentary structures between the heavily sheared grains [2] remains unclear.

Figure 4 shows the texture of the worked specimens. The centre of the pole figures corresponds to the direction normal to the specimen surface (ND). The top and right of the pole figures correspond to the rolling direction (or extrusion direction, ED) and transverse direction (TD) respectively. The textures of the two 90\% cold worked specimens (PH0.9 and EP0.9) exhibit similar rolling textures with the $\{110\}$ pole figures showing intensity around the rolling direction with four peaks located around $30^{\circ}$ from both $\mathrm{RD}$ and $\mathrm{TD}$. This means the rolling direction is parallel to the $<1 \overline{1} 0>$ crystal directions. The $\{001\}$ pole figures show that the maximum texture is located at the centre of the pole figure, which indicates that the $\{001\}$ planes align preferentially with the rolling plane. These results suggest that a $\{001\}<1 \overline{1} 0>$ texture is formed in the cold rolled specimens, in 
agreement with $b c c$ rolling textures in other materials [26]. The texture of EP3.5 is less strong than EP0.9, even though it has been subjected to a higher degree of deformation. It is thought that the texture produced by the swaging step would be distinctly different to that created by cold rolling. Evidently rolling from $4 \mathrm{~mm}$ diameter swaged bar to $1 \mathrm{~mm}$ thick sheet provided insufficient cold work to establish a rolling texture similar to that of EP0.9 and PH0.9.

The IM0.0 specimen exhibits a circularly symmetric texture which is overall weaker than that of the cold worked specimens. However, a greater proportion of the $<1 \overline{1} 0>$ crystal direction lies parallel to the primary deformation direction compared to the cold rolled textures.

\section{2 in-situ Synchrotron XRD}

Figure 5 shows the tensile load - unload curves of the Gum metal specimens. The effect of chemical composition, prior deformation and processing route on the macroscopic properties of these alloys has been discussed elsewhere [10]. Figure 5(a) shows that the first loading cycle of the EP0.0 specimen shows a linear response during both loading and unloading. However, during subsequent cycling both the loading and unloading curves show non-linearity.

In contrast, the first load cycle of the EP0.9 and EP3.5 specimens exhibit non-linear behaviour, as do all subsequent cycles. The non-linear unloading is more apparent in these specimens, with evidence of strain recovery especially in the later unload cycles. The behaviour of the PH0.0 and PH0.9 specimens is very similar to that of EP0.0 and EP0.9, respectively. However, the extent of nonlinearity in the EP condition is more pronounced.

Finally, the deformation of the IM0.0 specimen also shows non-linear behaviour. During the load cycles there is evidence of two gradients, albeit the transition from one to the other is gradual. The stress at which this transition occurs seems to decrease for each load cycle. Such observed loading - unloading behaviour is less distinct in other specimens.

Figure 6 shows the diffraction patterns of the specimens at three points during the strain to failure tests. The stress-strain curves of these tests are presented elsewhere [10]. In all specimen 
conditions there is evidence of a stress-induced phase transformation, which appears as new partial ring segments during loading.

Figure 7 shows that the stress-induced phase transformation in Gum metal is the orthorhombic martensite phase $(\alpha ")$. This phase transformation was observed in all specimen conditions regardless of the amount of prior deformation, the processing route and chemical composition.

In order to analyse the transformed peaks, Figure 7, the SXRD diffraction patterns (Figure 1) were segmented or 'binned'. This was because when the whole diffraction ring was integrated the intensities of the transformed peaks were relatively weak. In addition, since the peaks were fitted under stress, the Poisson's ratio effect caused apparent peak splitting of the $b c c$ peaks when integrating the entire diffraction rings. Due to the textured nature of the phase transformation, the $\alpha "$ variants were present at specific locations in the diffraction rings. Consequently, it was necessary to take a $\sim 35^{\circ}$ segment of the diffraction pattern, as smaller segments (e.g. $10^{\circ}$ ) only yielded singular transformed peaks. Such a bin angle was selected as this contained up to six transformed peaks that could be fitted. The diffraction patterns were fitted at load, when the transformed peaks were at their most intense. Consequently the peaks of the beta phase had shifted according to the material's anisotropy [10]. The peaks of the $\alpha$ " phase could not be fitted after the tests, due to the reversible nature of the phase transformation, Figures 6 and 8; although the EP3.5 specimen exhibited $\alpha$ " peaks at zero load, these peaks were sparse and of very low intensity.

Figure 7 shows an intensity-2 $\theta$ output from GSAS [27] of the IM0.0 specimen. This diffraction pattern was acquired from a $35^{\circ}$ segment of the diffraction pattern, between $20^{\circ}$ and $55^{\circ}$ from the tensile axis, at $6.9 \%$ strain $(840 \mathrm{MPa})$. The peak positions of the $\beta$ parent phase and the transformed $\alpha$ " phase are labelled. The peaks were fitted using a Le Bail peak fit in GSAS. The SXRD spectra of the cold worked alloys (EP0.9, EP3.5 and PH0.9) were very similar to the pattern in Figure 5. However, the $\{021\}_{\alpha^{\prime \prime}}$ peak was not present in these traces. This is thought to be a result of specimen texture combined with the variant selection process. In addition the intensity of the transformed peaks was greater in EP3.5 compared with EP0.9, which was greater than those of PH0.9. 
At zero load, the diffraction pattern of the EP0.0 specimen (Figure 6) reveals the presence of only $b c c$ rings, which are quite spotty due to the relatively coarse grain size of this material, as shown in Figure 2(a). The diffraction pattern just before failure reveals the presence of the transformed $\alpha$ " phase which appears at a higher angle than the inner-most $\beta_{110}$ ring, around the tensile direction. This

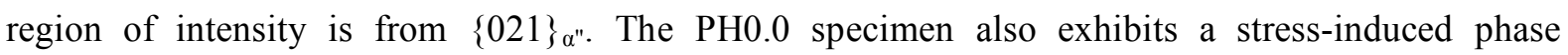
transformation, although it appears less intense and can only be seen inside the third peak $\left(\beta_{211}\right)$, which corresponds to $\{130\}_{\alpha^{\prime \prime}}$

The phase transformation is also evident in the EP0.9, EP3.5 and PH0.9 specimens in Figure 6. However, there are two distinct differences compared to the unworked (EP0.0 and PH0.0) specimens. Firstly the $\alpha$ " phase populates at specific locations in the diffraction pattern. This is presumed to be due to the different texture of the specimens combined with the variant selection process of $\alpha$ ". Secondly, the intensity of the new phase is higher in the cold rolled condition. This indicates that its formation is related to the amount of cold work, which is also supported by the fact that the intensity of the transformed phase is greater in EP3.5, compared to EP0.9. Figure 6 shows that there are traces of $\alpha^{\prime \prime}$ in the EP0.9 and EP3.5 specimens, before loading has commenced, indicating that the phase transformation was induced by cold rolling. The intensity of the transformed phase appears higher in the EP condition compared with the PH condition.

Finally, the phase transformation is also evident in the IM0.0 specimen, although the (110) a" $^{\prime \prime}$ peak is not as evident. The intensity of the transformed phase increases during loading and decreases after failure in all specimens, indicating that the phase transformation is reversible and therefore that Gum metal is superelastic.

Figure 8 shows the change in intensity of the $\alpha$ " phase in the Gum metal specimens during the cyclic loading tests presented in Figure 5. The $\{110\}_{\alpha^{\prime \prime}}$ peak of the PH0.9 specimen could only be fitted during the second loading cycle, suggesting that $\alpha^{\prime \prime}$ is difficult to detect in this specimen. After unloading in ramp two, the intensity of the $\{110\}_{\alpha^{\prime \prime}}$ peak reduces indicating the phase transformation is reversible. The superelastic behaviour is more pronounced during ramps three and four. The intensity of the $\{110\}_{\alpha^{\prime \prime}}$ peak also increases with strain at stresses near the tensile strength $(\sim 1200$ 
MPa). The EP0.9 specimen shows similar behaviour to PH0.9, however, the $\{110\}_{\alpha^{\prime \prime}}$ peak could be fitted during the first load cycle, which indicates that this condition is more susceptible to transformation, in agreement with the results in Figure 6. One feature, which is more evident in the EP0.9 condition, is that in ramp four, the intensity of the transformed peak is higher at a given stress compared to ramp three. This indicates that the transformation is aided by plastic strain.

The intensity of the $\alpha "$ phase is much greater in EP3.5, with a clear acceleration in the intensity at approximately $900 \mathrm{MPa}$ in ramp three. Again, there is an increase in the intensity at a given stress during cycling, which is more pronounced compared with EP0.9. The fact that the transformed peak can be fitted at zero load in the EP condition in Figure 8, supports the evidence in Figure 6 that the $\alpha$ " phase is stress induced during rolling.

The peak fitted for the IM0.0 specimen is the $\{021\}_{\alpha^{\prime \prime}}$ and the diffraction patterns were analysed using a $5^{\circ}$ bin, at an angle between $25-30^{\circ}$ from the rolling direction. Although the $\{110\}_{\alpha^{\prime \prime}}$ peak could be fitted, it could only be done so during ramp three. The $\{021\}_{\alpha^{\prime \prime}}$ peak could be fitted during the second ramp and is therefore presented in figure 8 , as more information can be acquired about the phase transformation. It is thought that the reason why the $\{110\}_{\alpha^{\prime \prime}}$ peak could only be fitted during the third ramp cycle is due to a texture effect. During the first load cycle in Figure 5(f), the elastic curve starts to deviate from linearity at $\sim 300 \mathrm{MPa}$. This point would be expected to be the stress at which stress-induced martensite forms $\left(\sigma_{\mathrm{SIM}}\right)$. However, as Figure 8 shows, the peak could only be fitted at $500 \mathrm{MPa}$. This suggests that the material is transforming before the peaks are detectable using SXRD, demonstrating a low volum e percent transformation during the early stages of the transformation. No other transformed peaks could be fitted at stresses below $500 \mathrm{MPa}$. Another feature of the phase transformation in IM0.0 is the change in the gradient of the intensity with stress, which is very steep. This observation is consistent with the macroscopic behaviour in Figure 5(f), where there is a distinct bend in the stress-strain response, which is more pronounced when compared to the other specimens in Figure 5.

The intensities of the $\alpha$ " phase in the IM0.0 condition merges with the background at about $500 \mathrm{MPa}$ during unloading in ramp two. This indicates that this transformation appears almost 
completely reversible in this condition, when unloading from this strain. This is supported by Figure 5(f), where there is only a small amount $(\sim 0.4 \%)$ of residual strain present when unloading from $4 \%$ nominal strain. The $\{021\}_{\alpha^{\prime \prime}}$ peak can be fitted at lower stress levels in ramps three and four, compared to ramp two. This is again consistent with the macroscopic response in Figure 5(f), i.e. the stress at which deviation from linearity occurs decreases in each cycle. However, during unloading in ramps three and four, the intensity only merges with the background at near zero stress. The phase transformation in the IM0.0 specimen seems to be more pronounced, compared to the other specimens. As the oxygen content is the same as the EP condition, oxygen cannot be responsible for this effect.

The intensities of all the transformed peaks in XRD are relatively low, even at peak load and even when the diffraction pattern is segmented to contain the region where the phase transformation is most intense. As mentioned above, the phase transformation can only be detected at stresses above which it starts appearing, indicating the low volume fraction of the transformed phase.

Figure 9 shows the change in the apparent lattice strain with stress for EP3.5 and IM0.0. The presence of the phase transformation at slightly higher $d_{h k l}$ values is causing the apparent position of each of the peaks to shift to higher $d_{h k l}$ values [10]. As the intensity of the transformed phase increases, the fitted peak has a higher apparent lattice strain, which explains the bending of the curves in Figure 9. Consequently, these curves do not give an accurate description of the microscopic deformation behaviour of the beta phase.

In Figures 9(a), (b) and (c), the first two loading cycles of the EP3.5 specimen show bending due to the phase transformation. The unloading curves exhibit nonlinearity back to $0 \%$ lattice strain demonstrating the reversible nature of the phase transformation. The third load-unload cycle in Figure 9(a) shows some recovery strain, although there is some residual lattice strain $(\sim 0.5 \%)$. The fourth load cycle (loading to $8 \%$ nominal strain), therefore commences at $0.5 \%$. Figure 8 shows, the cause of at least some of this residual lattice strain is due to some residual amount of the transformed phase.

The response of the $\{110\}$ orientation to stress in the IM0.0 condition is similar to that of EP3.5. One noticeable difference, however, is there is a higher degree of bending in IM0.0 as shown 
in Figure 9(d). This could be a result of a texture effect, however, given the macroscopic response to stress (Figure 5) of the two conditions and the microscopic response in other orientations in Figure 9, it is hypothesised that this effect is due the phase transformation being more pronounced in the IM0.0 condition.

Figure 9 also shows conventional yielding in both conditions, as indicated by the compressive lattice strains in the unloading curves; e.g. Figures 9(e) and (f). There is also evidence of load partitioning in Figure 9, as indicated by the bending of the stress-lattice strain curves to higher strains. However, the bending in these curves occurs below $400 \mathrm{MPa}$, well below the macroscopic yield stress of this material $[1,2]$. It is therefore concluded that the observed bending is mainly due to the effect of the phase transformation.

Although the IM0.0 specimen has a slightly lower Mo Eq than the EP condition, , it is thought that this would not be significant. A slight decrease in the beta stability, such as this, would be expected to change only the stress at which deviation from linearity occurs and not the extent of deviation. Therefore, it is considered that the processing route and the specifically the texture are responsible for this effect. It can be seen in Figure 9 that the $\{110\}$ orientation in each condition, exhibits the greatest lattice strain (as is the case in EP0.9 and PH0.9). Therefore, it is apparent that there is a large amount of the transformed phase growing at the shoulder of the $\{110\}_{\beta}$ peak. As the $\{110\}_{\beta}$ peak is very intense in the longitudinal direction in the diffraction pattern (as demonstrated in Figures 1 and 7), the phase transformation must also be intense to cause the observed bending. Therefore, it seems that a $[110]_{\beta}$ texture is desirable to obtain the most transformed elastic strain. This is in agreement with other studies which have studied the orientation dependence of the transformation strain in superelastic $\beta$ Ti alloys $[15,28,29]$.

The fact that the phase transformation seems largely reversible in this condition could be explained by the fact that this material has been hot worked. Although in Figure 8, evidence suggests that the intensity of the transformed peak is related to the amount of plastic strain, it appears that defects induced by the application of cold work serve to pin the transformed phase, which explains why there is a residual amount on unloading in the cold worked specimens. However, hot working via 
extrusion would allow dislocation recovery and hence fewer obstacles would be present to pin the phase transformation, upon reversion. The defects created by cold working are discussed in more detail in section 3.3 .

Figure $10(\mathrm{a}-\mathrm{c})$ shows the change in microstructure of $\mathrm{Ti}-29 \mathrm{Nb}-13 \mathrm{Ta}-4.6 \mathrm{Zr}$, before and after loading. Figure 10(a) shows the as-cast microstructure of Ti-29Nb-13Ta-4.6Zr, revealing the presence of large beta grains (The black features present in this figure are believed to be pits due to the lengthy etching time required for these alloys). After tensile testing, Figure 10(b), the microstructure consists of martensite laths and/or $b c c$ twins [30]. The in-situ XRD profile from this specimen at 5\% nominal strain confirms that the features are $\alpha$ " laths. The lattice parameters of the $\alpha$ " phase in this alloy are a $=3.18, \mathrm{~b}=4.82$ and $\mathrm{c}=4.68$ [31]. The $\alpha "$ phase is fairly easy to distinguish in XRD because of the occurrence of five characteristic peaks at low angles [30]. In Figure 10(c), only the $\{111\}_{\alpha^{\prime \prime}}$ can be seen, presumably because of the large grain size of this alloy, meaning very few grains are sampled and hence not all $\alpha^{\prime \prime}$ variants would be visible. In addition some $\alpha^{\prime \prime}$ variants may not be visible because the diffraction pattern has been segmented.

Figures 10(c) and (d) shows the change in microstructure of EP0.0 specimen. After failure, Figure 10(d), the microstructure near the fracture surface reveals the presence of banded structures, similar to those seen in Figures 2(b) and (e). At higher magnifications, there is evidence of very fine twins, or $\alpha^{\prime \prime}$ lath-like structures. The XRD profile of this specimen at $15 \%$ nominal strain, Figure $10(f)$, shows the presence of a $\{021\} \alpha$ " peak. It is clear that the size of the $\alpha$ " laths is much greater in Ti-29Nb-13Ta-4.6Zr, suggesting that the growth of the $\alpha$ " is restricted in Gum metal.

Previously, it has been observed in Ti-30Nb-3Pd that there was an increase in the volume fraction of $\alpha "$ at the edge of specimens due to higher quench rates [32]. In addition it is feasible that surface finishing may affect the amount of $\alpha$ " observed. However, in this study such surface effects are considered to be negligible as the X-ray beam is transmitted through the sample, meaning a $10 \mu \mathrm{m}$ surface layer only represents $\sim 1 \%$ of the volume scanned. Furthermore, it is clear in some specimens, e.g.EP0.0 that there is no $\alpha^{\prime \prime}$ before loading, but then it appears at some stress and its intensity decreases. 


\subsection{TEM}

The TEM diffraction pattern of the EP0.0 specimen in Figure 11(a) shows streaking towards $<\overline{1} 12>_{\beta}$, which is characteristic of the $\omega$ phase. This phase has formed after quenching from the solution treatment and is therefore the athermal omega phase $\left(\omega_{\text {ath }}\right)$. Direct imaging of the $\omega_{\text {ath }}$ precipitates was not possible, however. Figure 11(b) appears to show that the intensity of the $\omega_{\text {ath }}$ phase has increased after $90 \%$ cold work, suggesting that the $\omega_{\text {ath }}$ is stress-induced. The $\omega$ phase was also more intense in the diffraction patterns of the IM0.0 specimen, compared to EP0.0, Figure 11(c).

An increase in the intensity of the $\omega_{\text {ath }}$ phase after deformation has been observed by several investigators [33-35] in $\beta$ Ti alloys. In these studies the reason for the formation of the stress-induced $\omega$ after rolling was not understood.

Figure 12(a) is a TEM bright field image showing $\omega_{\text {ath }}$ quenched-induced plates in the EP0.0 specimen. This bright field image was taken with the beam direction close to $[110]_{\beta}$. The $[110]_{\beta}$ diffraction pattern is presented in Figure 12(b). The intensity of one of the $\omega_{\text {ath }}$ variants (labelled $\omega 1$ ) is stronger than the other. Figure 12(c) shows a dark field image taken from the $(0001)_{\omega}$ spot. Diffraction analysis reveals that the orientation of the plate-shaped $\omega$ phase and the $\beta$ matrix is slightly shifted away from the well established $<0001>_{\omega}\left\|<111>_{\beta} ;\{11 \overline{2} 0\}_{\omega}\right\|\{1 \overline{1} 0\}_{\beta}$ orientation relationship. It was apparent that there was a higher volume fraction of stress-induced plates in the cold worked and extruded specimens compared to EP0.0 and PH0.0.

Figure 13 shows the presence of twins in the EP0.9 specimen. Analysis of diffraction pattern in Figure 13(b), as well as others, indicate that the twins that form are of the type $\{112\}<111>$. The diffraction pattern key diagram in Figure 13(e) shows that the twinned $b c c$ reflections are in the same positions as the $\omega_{\text {ath }}$ matrix reflections. The intensity of the $\omega$ phase appears very similar in the matrix and twin.

Figure 14 shows faults in the IM0.0 specimen, which are comprised of stress-induced $\omega$ plates. The orientation of these plates is close to $\left\langle 111>_{\beta}\right.$. Figure 15 shows the same area as that in Figure 14, but with the beam direction close to $[001]_{\beta}$. It can be seen that the fault planes either side of the $\omega$ plates are composed of plate-like features, which traverse across the fault plane and terminate at 
the neighbouring $\omega$ plate. It appears that each fault plane is composed of a singular variant of the plate.

Figure 16 gives a clearer view of how the plates are distributed along the fault planes. It is evident that the plates align across the whole fault plane.

Figure 17 is a lower magnification bright field TEM image from the same area as Figure 14 and 15. As the features are tilted in the TEM the morphology of the faults appear more like steps. The steps are $\sim 200-400 \mathrm{~nm}$ in width and the plate features comprising the step or fault planes can still be observed. These steps are similar in size and morphology to the giant faults observed previously in Gum metal whose formation was regarded as being due to ideal shear [1-3].

Figure 18 shows that the one of the fault planes from Figure 17 is comprised of one variant of the $\omega_{\text {ath }}$ phase. It is apparent that one variant of the $\omega_{\text {ath }}$ phase is stronger in the diffraction pattern in Figure 18(c). Diffraction analysis revealed that the other plane comprising the faults also consists of a single variant of the $\omega$ phase.

Figure 19 shows another set of images from the faults in Figure 17. The diffraction pattern in Figure 19(c) shows that when the beam direction is close to $[110]_{\beta}$, reflections from $\alpha$ ", in addition to the $\omega$ phase are present. Figure 19(b) shows that the plates on the fault planes are composed of $\alpha "$ variants. One of the fault planes comprises the $[020] \alpha$ " variant and the other comprises the $[\overline{3} 10] a$ ".

Figure 20 is a bright field TEM image showing a twinned area of the EP0.9 specimen. Figures 20(c)-(e) show that there are reflections from the $\omega$ and $\alpha "$ phases in the diffraction pattern in Figure 20(b). Furthermore, there are $\alpha^{\prime \prime}$ reflections from both the $b c c$ matrix and the twinned lattice. However, within the twinned lattice only one variant of the $\alpha^{\prime \prime}$ phase is present, although it appears more intense than the $\alpha$ " reflections in the matrix. This implies that the advent of twinning has induced the formation of the $\alpha^{\prime \prime}$ phase. Similar behaviour has been observed in $\beta$ Ti binary alloys, where twinning was found to induce the formation of one variant of the $\omega$ phase [36].

\section{Discussion}




\subsection{The $\beta-\alpha "$ Transformation}

Figure 7 reveals that the stress-induced phase transformation in Gum metal is due to orthorhombic martensite ( $\alpha$ "). This is in agreement with many other $\beta$ Ti alloys of similar $\beta$ stability, e.g. Ti-22Nb-6Ta (at.\%) [15], Ti-26Nb (at.\%) [29], Ti-29Nb-13Ta-4.6Zr [31] and Ti-22Nb-2O (at.\%) [37]. Lattice paramaters of the $\alpha^{\prime \prime}$ were fitted for the IM0.0 and EP3.5 specimens as these exhibited the most intense transformed peaks. The average $\alpha^{\prime \prime}$ fitted lattice parameters for Gum metal are $a=$ $3.250 \AA, b=4.853 \AA, c=4.740 \AA$. The fitted lattice parameter of the $\beta$ phase at load was $3.347 \AA$. There was an average of a $1 \%$ difference between the $\alpha$ " lattice parameters between IM0.0 and EP3.5. One possible reason for the difference between the two specimens is that the IM0.0 specimen contains 1.9 wt.\% less $\mathrm{Nb}$ than Toy3.5. The fitted lattice parameters are in reasonable agreement with the similarly stabilised alloy Ti-29Nb-13Ta-4.6Zr [31].

\subsection{Prior Deformation}

The fact that stress increases linearly with strain in the EP0.0 specimen during the first loading cycle, but then shows non-linearity during the second cycle, is thought to be due to the formation of dislocations during the first cycle. Similar behaviour has been observed during cyclic loading of the alloy $\mathrm{Ti}-30 \mathrm{Nb}-10 \mathrm{Ta}-4 \mathrm{Zr}$ (wt.\%) [38] and was attributed dislocations formed during the first cycle, providing nucleation sites for $\alpha "$ during subsequent loading. The extent of gradient change is not as pronounced in Gum metal, compared with Ti-30Nb-10Ta-4Zr (wt.\%) [38], which could be due to the effect of oxygen inhibiting the growth of the $\alpha$ " laths (section 4.4). The fact that there is hardly a gradient change visible in the PH0.0 curve, Figure 5, supports this claim as this specimen is richer in oxygen compared to the other specimens. Another reason that may limit the amount of $\alpha^{\prime \prime}$ is a high triggering stress for stress induced martensite SIM $\left(\sigma_{\text {SIM }}\right)$ relative to the stress at which permanent deformation occurs. However, the fact that bending of the microscopic (Figure 9) and macroscopic stress-strain curves (Figure 5) occurs at approximately $400 \mathrm{MPa}$ in the EP condition, suggests that this is not the reason for the apparent lack of $\alpha$ " growth. 
Other evidence to support the importance of defects in activating the $\beta-\alpha$ " transformation is that the intensity of $\alpha^{\prime \prime}$ increases with cold work in Figure 6 . For example the intensity of $\alpha$ " increases from EP0.0 to EP0.9 to EP3.5. This is supported by the greater peak intensity of (110) $)_{\alpha^{\prime \prime}}$ observed in the EP3.5 specimen, compared to EP0.9, Figure 8. Also, the intensity of the $\alpha$ " peaks increase at a given stress during cycling, as more dislocations are induced. This is especially evident in ramps three and four, in the case of the EP0.9, EP 3.5 and IM0.0 specimens. This explains why the recovery strain $\left(\varepsilon_{\text {rec }}\right)$ increases with strain in Figure 5. Similar effects have been observed by other workers, investigating the effect of the amount of prior deformation on the recovery strain [39].

It seems that a critical amount of prior deformation, or a critical dislocation density is required to trigger the $\beta-\alpha^{\prime \prime}$ transformation. The higher dislocation density in the cold worked specimens is therefore thought to be the reason why non-linear elasticity is observed during the first loading cycle in Figure 5. This may explain why only non-linear elasticity was observed after the application of cold work in previous studies on Gum metal, and why it has been suggested that cold work is a necessity in achieving the 'superproperties' in this material [1,2].

\subsection{Effect of Oxygen on Superelastic Strain}

Although no extensometer was used during tensile loading, (meaning no accurate determination of the Young's modulus could be obtained), the actual elastic strain can be estimated, with knowledge of the specimens' true Young's modulus. The bulk Young's modulus of the specimens, which was calculated by taking a weighted average of the diffraction elastic constants, based on specimen texture, has been presented elsewhere [10]. From these values an estimate for recovery strain $\left(\varepsilon_{\text {rec }}\right)$, after unloading from $8 \%$ nominal strain (Figure 5 ) can be acquired, Table 3.

Prior work on $90 \%$ cold swaged Gum metal showed that this material had a $2.5 \%$ superelastic strain $[1,2,9]$, in reasonable agreement with the data in Table 3 . The slight difference could be a combination of the error associated with the values in Table 3, with respect to correction for machine stiffness, and the fact that a $90 \%$ swaged and a $90 \%$ rolled material should exhibit a different texture. 
No texture data has been given in previous work for the swaged specimens of Gum metal, meaning it is difficult to quantitatively compare the results.

The PH0.9 specimen shows the lowest recovery strain of the worked specimens, and therefore appears to be the least susceptible to transform to $\alpha "$. This effect is also apparent in other figures, e.g. the intensity of the transformed $\alpha$ " phase is greater in the EP condition in Figures 6 and 8, compared to in PH0.9. In the case of the EP0.9 and PH0.9 specimens, both have very similar textures (Figure 4) and Mo Eq values ( ). It is considered that this behaviour is therefore due to the amount of oxygen. It is well known that oxygen stabilises the $\beta$ phase during deformation $[37,40]$. In previous work the authors have shown that the PH0.9 specimen exhibited a higher $C^{\prime}$ and a higher $C_{44}$ compared to the EP0.9 specimen. It is therefore rational to consider that the greater oxygen content in the PH condition has increased the materials resistance to the SIM transformation, by increasing the magnitude of $G_{110}$ $\left(C^{\prime}\right)$ and $\mathrm{G}_{001}\left(C_{44}\right)$. This explains the more pronounced macroscopic (Figure 6) and microscopic (Figure 9) bending of the EP specimens in the stress-strain curves.

Ren and Otsuka [14] found that the monoclinic martensite structure B19' in TiNi alloy stems from a coupling between $C^{\prime}$ shear and $\mathrm{C}_{44}$ shear, in which the $C_{44}$ shear $\{001\}<1 \overline{1} 0>$ creates the monoclinic distortion to the otherwise orthorhombic structure B19. The occurrence of these martensites seem to be specific to the Ti-Ni system, and are thought to be a consequence of TiNi's low $C_{44}$, in view of the fact that other $b c c$-based superelastic alloys exhibit harder values (Table 1 ). Although Gum metal exhibits a lower $C_{44}$ than NiTi (Table 1), the fitted crystal structure of the martensite phase is orthorhombic, Figure 5, in agreement with other $\beta$ Ti alloys $[15,29,31]$. Consequently, it appears that the non-basal $C_{44}$ shear is not involved in the formation of $\alpha$ " in Gum metal. Further work is needed to understand why $\{001\}<1 \overline{1} 0>$ shear does not occur in the formation of martensite in these alloys. Therefore the suppression of the $\beta-\alpha$ " transformation in Gum metal must arise from a hardening of $C^{\prime}$, caused by oxygen [10].

This is supported by the data in Table 1 , which shows that $C^{\prime}$ increases from $8 \mathrm{GPa}$ in Ti$22 \mathrm{Nb}-6 \mathrm{Ta}$ (at.\%), to $16 \mathrm{GPa}$ in the EP condition, to $17.5 \mathrm{GPa}$ in the PH condition. Consequently it 
appears that the interstitial strengthening effect of oxygen [10] is offset by the hardening of $C^{\prime}$, reducing the susceptibility to transform. In addition to the higher resistance to shear caused by oxygen, it appears that the growth of the $\alpha^{\prime \prime}$ laths is restricted in Gum metal, limiting the amount of transformation strain. This is best illustrated in Figure 10, which shows that the $\alpha$ " is of a much finer scale compared to that in the alloy Ti-29Nb-13Ta-4.6Zr. This could be one of the reasons why Gum metal is still ductile after $90 \%$ cold work.

Given that there is a large stress window for the $\alpha^{\prime \prime}$ transformation to occur in Gum metal (compared to other superelastic $\beta$ Ti alloys) it is perhaps unexpected that this alloy still exhibits a relatively small transformation strain. This could be a consequence of the pinning effect of the $\omega_{\text {ath }}$ phase, seen in these alloys (section 3.3). However, other studies have shown that microstructures that contain the $\omega_{\text {iso }}$ phase can still exhibit high superelastic strains $(>3 \%)[29,41]$, despite their lower stress window than Gum metal. It therefore appears that other obstacles are pinning the growth of the $\alpha^{\prime \prime}$ in Gum metal. Previous work [1] has suggested that zirconium-oxygen clusters may form in this material, which may be responsible for this effect.

It should be highlighted that although the PH0.9 specimen shows the lowest strain recovery of the worked specimens, Table 3, it has a very similar value to the EP0.9 specimen, but is $\sim 130 \mathrm{MPa}$ stronger. This demonstrates the significance of oxygen addition to superelastic alloys, by increasing the stress at which permanent deformation can occur, whilst maintaining a high strain recovery [37]. It is thought that a higher oxygen content would also raise the triggering stress for the SIM transformation $\left(\sigma_{\mathrm{SIM}}\right)$ [37]. However, because of the continuous gradients of the macro- and microscopic stress-strain curves, it is difficult to verify this. In addition, there is no sudden increase in the intensity of the $(110)_{\alpha^{\prime \prime}}$ peak in the PH0.9b specimen in Figure 8, which would give an indication as to the value of $\sigma_{\mathrm{SIM}}$.

Previously, Gum metal compositions that contain no oxygen have been found to undergo a stress induced $\alpha$ " phase transformation, identified by laboratory XRD [2]. However, until now, the elastic deformation of Gum metal was not thought not to involve a stress-induced phase transformation. This suggests that the presence of oxygen, and the fact that the $\alpha$ " phase disappears 
upon unloading, have presented the difficulties in identification of $\alpha$ ". Another reason that may account for the non-detection of $\alpha$ ", is that previously, laboratory XRD has been used to analyse the in-situ loading response. However, because the incident beam can only penetrate the surface of the specimen, only grains with plane normals perpendicular to the tensile axis will obey Bragg's law. Consequently information cannot be acquired for grains with plane normals away from the transverse direction. Figure 6 shows that the $\alpha$ " phase populates at locations near the tensile axis, as well as at $\sim 45^{\circ}$ to the loading axis (i.e. near the plane of maximum shear stress). As the beam can propagate through the specimen in SXRD, grains of all orientations can diffract. This demonstrates one of the advantages of using SXRD over conventional laboratory XRD to evaluate in-situ response to stress.

\subsection{Texture}

The EP3.5 specimen exhibits the best combination of high superelastic strain, with high strength. As this specimen fails at a higher stress than EP0.9, there is a greater opportunity for the $\beta$ $\alpha^{\prime \prime}$ transformation to occur, increasing the amount of transformation strain. This is demonstrated in Figure 8 , where there is a clear acceleration in the intensity of the $(110)_{\alpha^{\prime \prime}}$ peak, near the ultimate tensile strength of this condition.

It is apparent that the IM0.0 specimen exhibits the greatest amount of transformation strain of the worked specimens as shown macroscopically by the higher degree of non-linearity in Figure 5. Although the IM0.0 specimen has a slightly lower Mo Eq this should only slightly change the triggering stress for the transformation and not the extent of deviation from linearity. The IM0.0 specimen has the same oxygen content as the EP condition, therefore this effect must be due to specimen texture. When analysing the textures of the specimens in Figure 4, it is apparent that in the IM0.0 specimen, the $<1 \overline{1} 0>$ crystal direction is parallel with the tensile axis, or rolling direction. In the cold rolled specimens (PH0.9b, EP0.9 and EP3.5), a large proportion of the $<1 \overline{1} 0>$ crystal directions are at angles $\sim 30^{\circ}$ from the tensile axis. It has been established that the $\beta$ - $\alpha$ " transformation strain ( $\varepsilon_{\text {trans }}$ ) is maximised along the $<110>$ crystal direction $[15,28,29]$. Consequently, it appears that the greater extent of transformation strain in the IM0.0 specimen can be attributed to a texture effect. 


\subsection{Formation of $\omega$ Plates and Deformation Twins}

As shown in section 3.3, stress-induced $\omega_{\text {ath }}$ plates form in Gum metal after quenching, and then more form during rolling or extrusion. Similar features have been observed previously in shock loaded $\mathrm{Zr}-\mathrm{Nb}$ alloys [42-44]. In these studies the stress-induced $\omega$ plates were found to contain one variant of the $\omega$ phase, in agreement with Figure 12. A $b c c$ structure can be described by a six-layer packing sequence of $\{112\}_{\beta}$ planes [42]. Hatt and Roberts [45] have examined the possibility of generating the $\omega$ structure by gliding a $\{112\}$ plane and have shown that a suitable sequence of glides can indeed produce the $\beta-\omega$ transformation. A macroscopic shear on a $\{112\}_{\beta}$ plane along a $<111>$ direction, superimposed with atomic shuffles, can produce the $\omega$ structure. Since the macroscopic deformation is a simple shear the invariant plane, which is the contact plane between the two phases, is the shear plane itself. Since any specific $\{112\}_{\beta}$ plane contains only one $<111>$ direction, a single orientational variant of the $\omega$ structure can be produced within a single $\{112\}_{\beta}$ plate. This conclusion is consistent with the TEM results in refs. [42-44]. Figures 12 and 14 show that the orientation of the plates are slightly shifted away from $\{112\}_{\beta}<111>$. Hanada and Izumi [36] have suggested that scatter in the determination of habit planes of stress-induced plates in $\beta$ Ti alloys maybe due to second order twinning or slip that distorts the original habit plane. Interestingly, previous work on Gum metal has shown that the orientation of the giant faults observed are close to $\{112\}_{\beta}<111>$, although no $\omega$ plates were seen $[1,3]$.

The formation of the chevron or 'zig-zag' shaped $\omega$ plates (Figure 16) is viewed as a coalescence of different variants of the $\omega$ phase [44]. There have been very few instances where these stress-induced $\omega$ plates form as a result of quenching. However, in Ti-30Nb-3Pd similar plates have been observed after quenching from $700-900^{\circ} \mathrm{C}$ [32]. No reason was offered as to why the plates were observed after quenching in Ti-30Nb-3Pd, although it was speculated that the addition of Pd was the cause, as these features have not previously been observed in quenched Ti-Nb binary alloys.

Due to the fact that these plates form via a mechanism involving shear of $\{112\}_{\beta}$ in the $<111>$ direction, their formation will be facilitated by a low $G_{111}$ and hence a low $C^{\prime}$ and $C_{44}$, Equation 2. 
$G_{111}=\frac{3 C_{44}\left(C_{11}-C_{12}\right)}{C_{11}-C_{12}+4 C_{44}}$

In Gum metal, it is likely that the formation of the $\omega_{\text {ath }}$ plates is due to a softening of $C^{\prime}$, in comparison to other $\beta$ Ti alloys [10]. However, this still does not explain why the stress-induced $\omega$ plates have not been observed in other alloys after quenching. Presumably, other $\beta$ Ti alloys with a low $C^{\prime}$ are also vulnerable to this phase transformation. Further work is needed to understand why these $\omega$ plates form, but it is suggested that TEM, in addition to XRD should be used to characterise these alloys, especially as they are so sensitive to stress-induced phase transformations. Usually XRD is solely used to characterise these materials, meaning that the $\omega$ plates may not be observed, as was the case in the SXRD spectra in the specimens in this study.

Figure 13 shows the appearance of $\{112\}<111>$ twins in the EP0.9 specimen. Such twins have been observed in conjunction with stress-induced $\omega$ plates in shock loaded $\mathrm{Zr}-\mathrm{Nb}$ alloys and their formation also involves shearing of $\{112\}_{\beta}$ planes. Hsiung and Lasilla [44] have seen extensive twinning and stress-induced $\omega$ in $b c c$ pure Ta and Ta-W alloys when the materials were subjected to shock loading. The mechanism for both stress-induced $\omega$ formation and twinning possess a common factor in the form of shear of $\{112\}_{\beta}$ planes [44], and is thus promoted by a low $G_{111}$.

\subsection{Mechanism of Superelasticity}

Based on the TEM images in section 3.3, the schematic diagrams in Figure 21 have been constructed. Figure 21(a) shows the formation of $\omega$ plates or $b c c$ twins, which both involve shear of $\{112\}_{\beta}$. During deformation, Figure 21(b), two $\alpha "$ variants, (one either side of the twin $/ \omega$ plate forming the fault) grow from the $\beta$ - $\omega$ or $\beta$-twin interface (Figure 20). During tensile loading, in order to accommodate further strain the interface between the $\alpha^{\prime \prime}$ variants is able to move, Figure 21(c).

Figure 21 represents an idealised concept of the stress-induced phase transformation in Gum metal. The role of the $\omega$ phase in this transformation requires further study. Figure 19 implies that the $\alpha$ " variants are also co-mingled with the $\omega$ plates, which may have been stress-induced during working. This is supported by the increase in the intensity of the $\omega_{\text {ath }}$ phase in the TEM diffraction 
patterns in Figure 11. It is not known if; (a) the $\alpha^{\prime \prime}$ variants consume these $\omega$ plates during deformation, and then untransform, either directly back to $\omega$ or via the $\beta$ phase upon unloading [4649]; or (b) SIM growth leaves the $\omega$ phase intact, presumably by nucleating on the $\beta$ - $\omega$ interface. In either case, there would be a small amount of the $\omega$ phase present, consistent with the observations in Figure 18. Other workers have observed similar behaviour, whereby the stress-induced $\omega$ plates form during quenching, which act as nucleation sites for the formation of SIM [50]. In ref. [50] the absence of the plate and particle-like $\omega$ phase after deformation was attributed to the $\omega$ phase transforming into $\alpha^{\prime \prime}$. However, it was suggested that that the structural change of $\omega$ to $\alpha^{\prime \prime}$ is difficult to achieve in comparison with $\beta-\alpha$ ". This is because the inverse structural change $\omega-\beta$ is necessary before the displacive $\beta-\alpha$ " martensite transformation. This would suggest that the $\omega$ variants may revert to $\beta$ before transforming to $\alpha "$. There is evidence in Figure 20 that the $\alpha$ " phase has consumed the $\omega$ phase, as there is obvious presence of the $\omega$ phase in the twinned diffraction pattern.

It is considered that the fault planes in Gum metal act like grain boundaries in agreement with hypotheses from previous work [3]. The fact that the diffraction patterns of PH0.0b and EP0.0 (Figure 6) become less spotty during loading suggests that substructures may be forming during deformation. The banded structures observed in light microscopy (Figures 2(b), 2(b) and 2(a)) are believed to be due to a set of fault planes induced after rolling, or are $b c c$ twins.

In summary, the results of this study and previous work $[10,11]$, show that Gum metal does not deform via ideal shear, but instead deforms via a stress-induced reversible phase transformation. In comparison to other $\beta$ Ti superelastic Ti alloys, Gum metal is stronger, but has a lower superelastic strain. This is due to the presence of oxygen which increases $C^{\prime}$, and limits the growth of $\alpha^{\prime \prime}$ and reduce the amount of transformation strain. The relatively low volume fraction of transformed $\alpha$ ", coupled with the fact that this phase is reversible, are the probable reasons why this deformation mechanism has not been identified previously. SXRD results show the phase transformation is also evident in specimens that have not been subjected to cold work, although cold rolling induces twins and stress-induced $\omega$ plates that facilitate the $\beta-\alpha$ " transformation. This suggests that cold work is not 
a requirement to produce non-linearity in the stress-strain curve in Gum metal. Finally, the effect of cold work on the mechanical properties, combined with the observation of dislocations in TEM suggests that Gum metal does not deform via a dislocation-free plastic deformation mechanism

\section{Conclusions}

This study has investigated the deformation mechanisms of the multifunctional Ti alloy, Gum metal using in - situ SXRD and TEM. The following conclusions can be drawn:

- Gum metal deforms via a stress-induced superelastic $\alpha$ " phase transformation. The fitted lattice parameters of the $\alpha^{\prime \prime}$ phase are $a=3.250 \AA, b=4.853 \AA, c=4.740 \AA$.

- Ingot metallurgy is a viable processing route for producing Gum metal, with the mechanical properties comparable with previous work.

- The superelastic strain in Gum metal is mainly due to the low Young's modulus and high yield strain of the $\beta$ phase, with only a small amount of transformation strain evident in the majority of specimens.

- Oxygen has a significant strengthening effect in Gum metal, although it seems to inhibit the amount of transformation strain by increasing $C^{\prime}$.

- Prior deformation aids the formation of SIM by providing nuclei for $\alpha$ " formation.

- The amount of transformation strain can be increased by optimisation of specimen texture. The IM0.0 specimen with a $<110>_{\beta}$ texture showed the most transformation strain.

- The $\omega_{\text {ath }}$ phase can form as stress-induced plates after quenching and during plastic deformation.

- Deformation twins, of the type $\{112\}<111>$ are observed after rolling. The mechanism for both stress-induced $\omega$ formation and twinning possess a common factor in the form of shear of $\{112\}_{\beta}$ planes, and is thus promoted by a low $G_{111}$. 
- The 'marble'-like microstructures in Gum metal have been reproduced. However, these microstructures are not believed to be specific to this material, as similar micrographs are observed in other $b c c$ metals and alloys after swaging or extrusion.

- The mechanism of the $\beta-\alpha$ " transformation is complex, but it appears that $\alpha$ " grows from the stress-induced $\omega$ plates or twins induced from quenching or working. Large scale growth of the martensite may be prevented by the $\omega$ phase or oxygen clusters.

- The giant faults observed previously in Gum metal are thought to be a result of the low value of $C^{\prime}$, which promotes shear in $\left\langle 111>_{\beta}\right.$.

\section{Acknowledgements}

The work reported in this paper was part funded by the Systems Engineering for Autonomous Systems (SEAS) Defence Technology Centre established by the UK Ministry of Defence and ONR (N00014-04-1-0155). The PH specimens were manufactured by Crucible Research, Pittsburgh, PA, USA and Bodycote HIP, Chesterfield, UK. The EP0.0 and EP3.5 specimens were supplied by the Toyota Central R\&D Laboratories. The ingot for the IM0.0 specimen was cast by Dr Mark Ward at the University of Birmingham, UK. The Ti-29Nb-13Ta-4.6Zr alloy was supplied by Takayoshi Nakano at the university of Osaka. The authors are grateful for the discussions with Shigeru Kuramoto of Toyota R\&D. Finally the authors acknowledge the help of Seema Raghunathan and Nicholas Jones.

\section{References}

1. Saito T, Furuta T, Hwang JH, Kuramoto S, Nishino K, Suzuki N, Chen R, Yamada A, Ito K, Seno Y, Nonaka T, Ikehata H, Nagasako N, Iwamoto C, Ikuhara Y, Sakuma T. Science 2003;300:464.

2. Furuta T, Nishino K, Hwang J, Yamada A, Ito K, Osawa S, Kuramoto S, Suzuki N, Chen R, Saito T. In: Lütjering G and Albrecht J, editors.Ti-2003 science and technology. Weinheim, Germany: Wiley-VCH; 2004. p. 1519. 
3. Kuramoto S, Furuta T, Hwang JH, Nishino K, Saito T. Metall. Mater. Trans. A 2006;37:657.

4. Kuramoto S, Furuta T, Hwang J, Seno Y, Nonaka T, Ikehata H, Nagasako N, Nishino K, Saito T, Iwamoto C, Ikuhara Y, Sakuma T. In: Lütjering G and Albrecht J, editors.Ti-2003 science and technology. Weinheim, Germany: Wiley-VCH; 2004. p. 1527.

5. Gutkin MY, Ishizaki T, Kuramoto S, Ovid'ko IA. Acta Mater. 2006;54:2489.

6. Li T, Morris JW, Nagasako N, Kuramoto S, Chrzan DC. Phys. Rev. Lett. 2007;98:105503.

7. Krenn CR, Roundy D, Morris J, J. W., Cohen ML. Mater. Sci. Eng., A 2001;319-321:111.

8. Ikehata H, Nagasako N, Furuta T, Fukumoto A, Miwa K, Saito T. Phys. Rev. B 2004;70:174113.

9. Kuramoto S, Furuta T, Hwang JH, Nishino K, Saito T. Mater. Sci. Eng., A 2006;442:454.

10. Talling R, Jackson M, Dashwood RJ, Kuramoto S, Dye D. Scr. Mater. 2008;

11. Talling R, Jackson M, Dashwood RJ, Dye D. In: Niinomi M et al., editors.Ti-2007 science and technology. Sendai, Japan: The Japan Institute of Metals; 2008. p. 631.

12. Brill TM, Mittelbach S, Assmus W, Mullner M, Luthi B. J. Phys. Condens. Matter 1991;3:9621.

13. Mercier O, Melton KN, Gremaud G, Hagi J. J. Appl. Phys. 1980;51:1833.

14. Ren X, Miura N, Zhang J, Otsuka K, Tanaka K, Koiwa M, Suzuki T, Chumlyakov YI, Asai M. Mater. Sci. Eng., A 2001;312:196.

15. Kim HY, Sasaki T, Okutsu K, Kim JI, Inamura T, Hosoda H, Miyazaki S. Acta Mater. 2006;54:423.

16. Suezawa M, Sumino K. Scr. Metall. 1976;10:789.

17. Prasetyo A, Reynaud F, Warlimont H. Acta Metall. 1976;24:1009.

18. Guenin G, Morin M, Gobin PF, Dejonghe W, Delaey L. Scr. Metall. 1977;11:1071. 
19. Nakanish N, Murakami Y, Kachi S. Scr. Metall. 1971;5:433.

20. Zirinsky S. Acta Metall. 1956;4:164.

21. Enami K, Hasunuma J, Nagasawa A, Nenno S. Scr. Metall. 1976;10:879.

22. Hammersley AP, Svensson SO, Hanfland M. High Press. Res. 1996;14:235.

23. Hammersley AP, Svensson SO, Thompson A. Nucl. Instrum. Methods Phys. Res., Sect. A $1994 ; 346$

24. Kallend JS, Kocks UF, Rollett AD, Wenk H-R. Mater. Sci. Eng., A 1991;132:1.

25. Sandim HRZ, McQueen HJ, Blum W. Scr. Mater. 1999;42:151.

26. Park YB, Lee DN, Gottstein G. Acta Mater. 1998;46:3371.

27. Larson AC, von Dreele RB. Los Alamos National Laboratory Report LAUR 1994:86.

28. Inamura T, Kinoshita Y, Kim JI, Kim HY, Hosoda H, Wakashima K, Miyazaki S. Mater. Sci. Eng., A 2006;438-440:865.

29. Kim HY, Ikehara Y, Kim JI, Hosoda H, Miyazaki S. Acta Mater. 2006;54:2419.

30. Williams JC. In: Jaffee RI and Burte HM, editors.Ti-1973 science and technology. New York, USA: Plenum Press; 1973. p. 1433.

31. Hao YL, Niinomi M, Kuroda D, Fukunaga K, Zhou YL, Yang R, Suzuki A. Metall. Mater. Trans. A 2002;33:3137.

32. Ping DH, Cui CY, Yin FX, Yamabe-Mitarai Y. Scr. Mater. 2006;54:1305.

33. Hida M, Sukedai E, Henmi C, Sakaue K, Terauchi H. Acta Metall. 1982;30:1471.

34. Matsumoto H, Watanabe S, Masahashi N, Hanada S. Metall. Mater. Trans. A 2006;37:3239.

35. Wood RM. Acta Metall. 1963;11:907. 
36. Hanada S, Izumi O. Metall. Mater. Trans. A 1986;17:1409.

37. Kim JI, Kim HY, Hosoda H, Miyazaki S. Mater. Trans. 2005;46:852.

38. Sakaguchi N, Niinomi M, Akahori T, Takeda J, Toda H. Mater. Sci. Eng., C 2005;25:363.

39. Laheurte P, Eberhardt A, Philippe MJ. Mater. Sci. Eng., A 2005;396:223.

40. Abdel-Hady M, Hinoshita K, Morinaga M. Scr. Mater. 2006;55:477.

41. Zhou T, Aindow M, Alpay SP, Blackburn MJ, Wu MH. Scr. Mater. 2004;50:343.

42. Dey GK, Tewari R, Banerjee S, Jyoti G, Gupta SC, Joshi KD, Sikka SK. Philos. Mag. Lett. 2002;82:333.

43. Dey GK, Tewari R, Banerjee S, Jyoti G, Gupta SC, Joshi KD, Sikka SK. Acta Mater. 2004;52:5243.

44. Hsiung LM, Lassila DH. Acta Mater. 2000;48:4851.

45. Hatt BA, Roberts JA. Acta Metall. 1960;8:575.

46. Li SJ, Niinomi M, Hao YL, Cui YY, Guo ZX. Mater. Sci. Technol. 2005;21:678.

47. Duerig TW, Middleton RM, Terlinde GT, Williams JC. In: Kimura H and Izumi O, editors.Ti-1980 science and technology. New York, USA: AIME; 1980. p. 1503.

48. Duerig TW, Terlinde GT, Williams JC. Metall. Mater. Trans. A 1980;11:1987.

49. Ohmori Y, Ogo T, Nakai K, Kobayashi S. Mater. Sci. Eng., A 2001;312:182.

50. Ping DH, Mitarai Y, Yin FX. Scr. Mater. 2005;52:1287. 
Table 1: Comparison of $C^{\prime}, C_{44}$ and $\tau_{\max }$ in Gum metal (EP0.9 and PH0.9 [10]) with those of other $b c c$-based superelastic alloys, adapted from Kym et al. [15].

\begin{tabular}{cccc} 
& $C^{\prime}(\mathrm{GPa})$ & $C_{44}(\mathrm{GPa})$ & $\tau_{\max }(\mathrm{GPa})$ \\
\hline EP0.9 [10] & 16 & 28 & 2.1 \\
PH0.9 [10] & 17.5 & 29 & 2.2 \\
\hline Ti-Ni [12-14] & $17-19$ & $35-39$ & 2.4 \\
Ti-22Nb-6Ta [15] & 8 & 21.3 & 1.1 \\
Cu-Al-Ni [16] & $7-8$ & 100 & 1.2 \\
Cu-Zn [17] & 8 & 90 & 1.3 \\
Cu-Zn-Al [18] & 5.8 & 86 & 0.9 \\
Au-Cu-Zn [19] & $3-5$ & 60 & 0.6 \\
Au-Cd [20] & $3-3.8$ & 42 & 0.5 \\
Ni-Al [21] & 14.6 & 132 & 2.3 \\
\hline
\end{tabular}


Table 2: Chemical compositions of the Ti-Nb-Ta-Zr-O alloys studied (wt.\%).

\begin{tabular}{ccccccccccccccc}
\hline & $\mathrm{Ti}$ & $\mathrm{Nb}$ & $\mathrm{Ta}$ & $\mathrm{Zr}$ & $\mathrm{O}$ & $\mathrm{V}$ & $\mathrm{Fe}$ & $\mathrm{Ni}$ & $\mathrm{Cu}$ & $\mathrm{Cr}$ & $\mathrm{e} / \mathrm{a}$ & $\mathrm{Md}$ & $\mathrm{Bo}$ & $\mathrm{Mo} \mathrm{Eq}$ \\
\hline Target & Bal. & 35.8 & 2.1 & 3.1 & 0.32 & & & & & & 4.24 & 2.45 & 2.87 & 10.4 \\
EP & Bal. & 36.9 & 2.0 & 3.0 & 0.3 & 0.09 & & 0.2 & 0.06 & 0.01 & 4.26 & 2.45 & 2.87 & 11.0 \\
$\mathrm{PH}$ & Bal. & 35.7 & 2.1 & 3.2 & 0.42 & 0.14 & 0.08 & 0.08 & 0.05 & 0.1 & 4.25 & 2.45 & 2.87 & 10.9 \\
$\mathrm{IM}$ & Bal. & 35 & 2.1 & 3.1 & 0.3 & 0.01 & 0.03 & 0.01 & & 0.02 & 4.23 & 2.45 & 2.87 & 10.3 \\
\hline
\end{tabular}


Table 3: Approximate values of the true recovery strain $\left(\varepsilon_{\text {rec }}\right)$ obtained from unloading from $8 \%$ nominal strain. These values have been corrected for machine stiffness (see text above).

\begin{tabular}{ccccccc}
\hline Specimen & Toy0.0 & Toy0.9 & Toy3.5 & HIP0.0b & HIP0.9b & IM0.0 \\
\hline$\varepsilon_{\text {rec }}$ & 1.5 & 1.9 & 2.2 & 1.3 & 1.8 & 1.9 \\
\hline
\end{tabular}



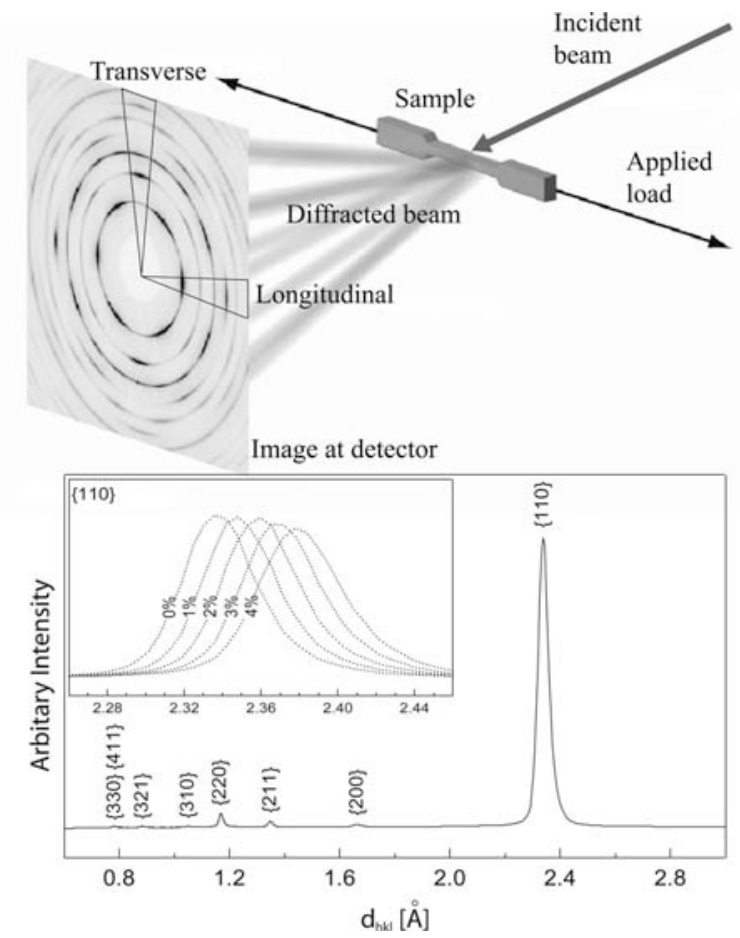

Figure 1: Schematic representation showing how diffraction rings are produced with a corresponding intensity $-d_{\mathrm{hkl}}$ plot. The position of each peak after each snap was determined and the lattice strain $\left(\varepsilon_{\mathrm{hkl}}=\Delta d / d_{0}\right)$ calculated and plotted as a function of stress. Inset; evolution of the $\{110\}$ peak with nominal strain in grains orientated with plane normals parallel to the loading direction. 


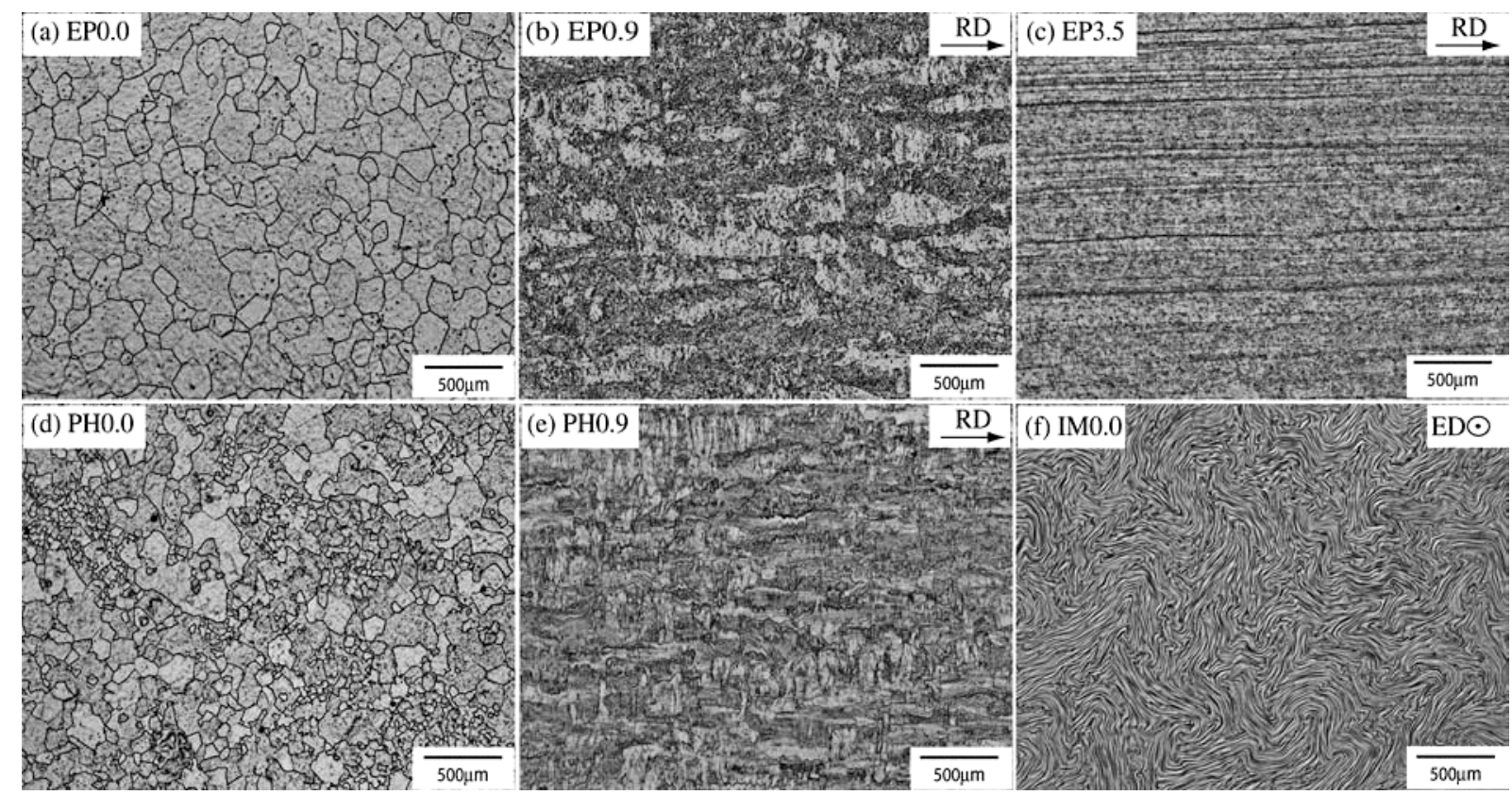

Figure 2: Light micrographs of specimens; (a) EP0.0; (b) EP0.9; (c) EP3.5; (d) PH0.0, (e) PH0.9 and; (f) IM0.0. The rolling direction (RD) and extrusion direction (ED) are labelled. 


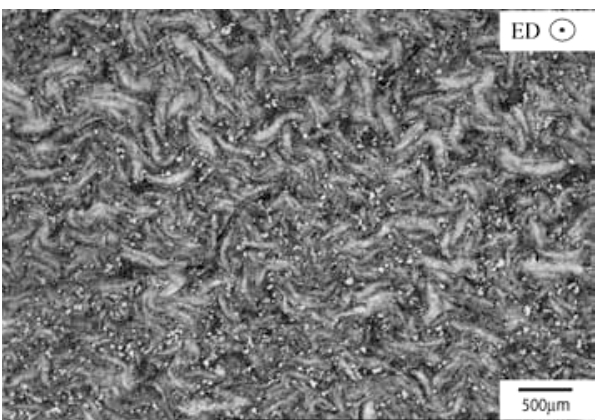

Figure 3: Optical micrograph of the transverse section of as extruded Ti-5Mo-5Al-5V-3Cr. The extrusion direction (ED) is shown. 

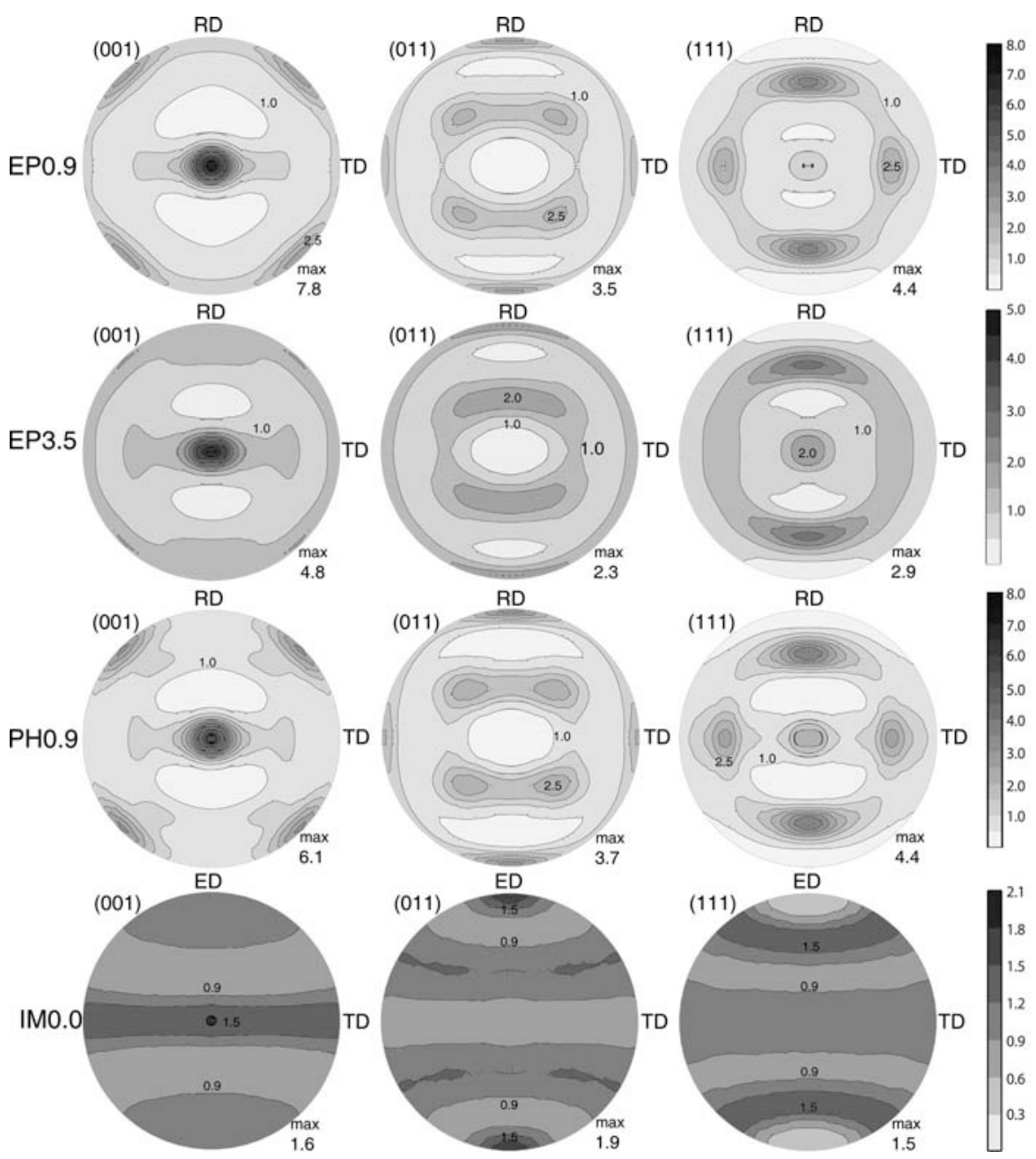

Figure 4: Pole figures of the EP0.9, EP3.5, PH0.9 and IM0.0 specimens. The rolling direction (RD) and the extrusion direction (ED) are shown. 


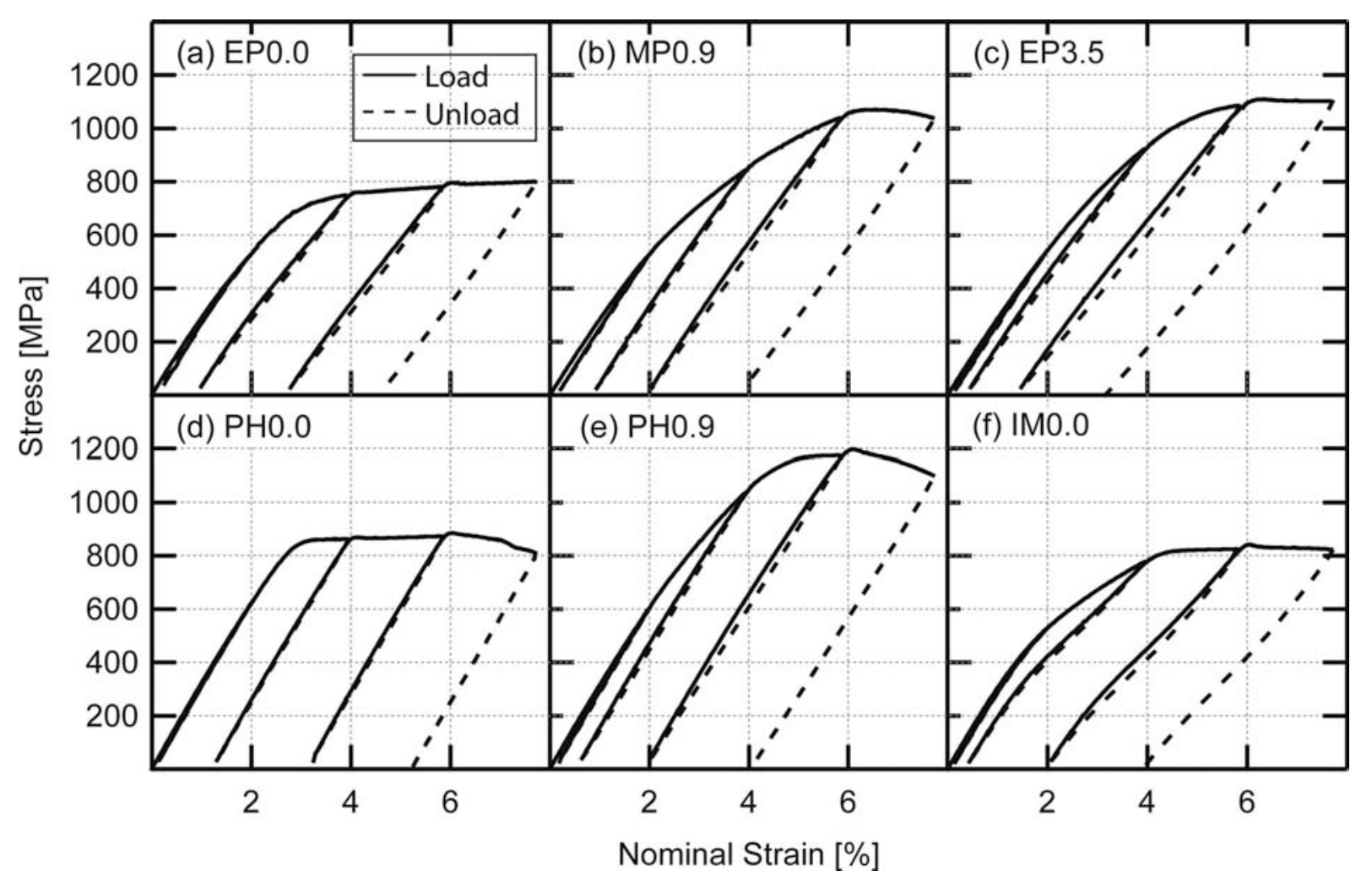

Figure 5: Tensile loading - unloading nominal stress - strain curves for each $\mathrm{Ti}-\mathrm{Nb}-\mathrm{Ta}-\mathrm{Zr}$ alloy. 


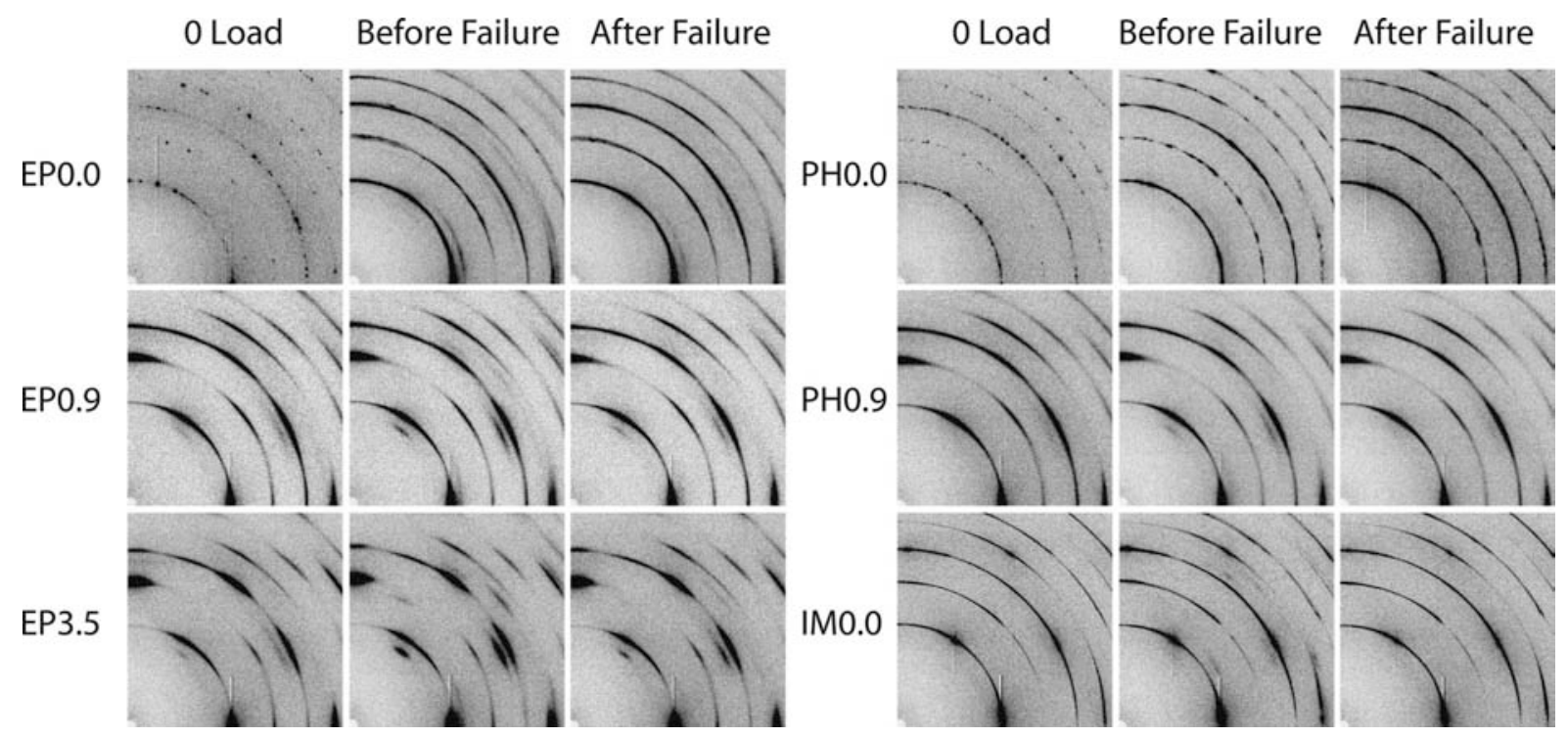

Figure 6: Diffraction pattern quadrants of all the specimens at zero load, just before failure and after failure when the load was removed. This data was taken from the strain to failure tests detailed in a previous study [10]. The tensile direction is from left to right. 


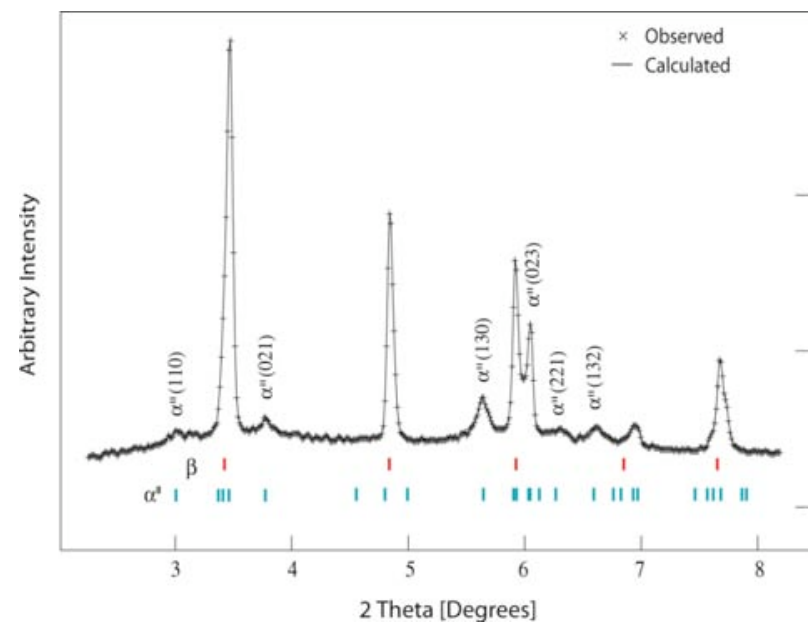

Figure 7: GSAS intensity-2 theta output of a diffraction pattern of the IM0.0 specimen taken at $6.9 \%$ nominal strain and between $20^{\circ}$ and $55^{\circ}$ from the tensile axis. The positions of the $\beta$ and $\alpha^{\prime \prime}$ peaks are labelled and the $\alpha^{\prime \prime}$ reflections are indexed. 


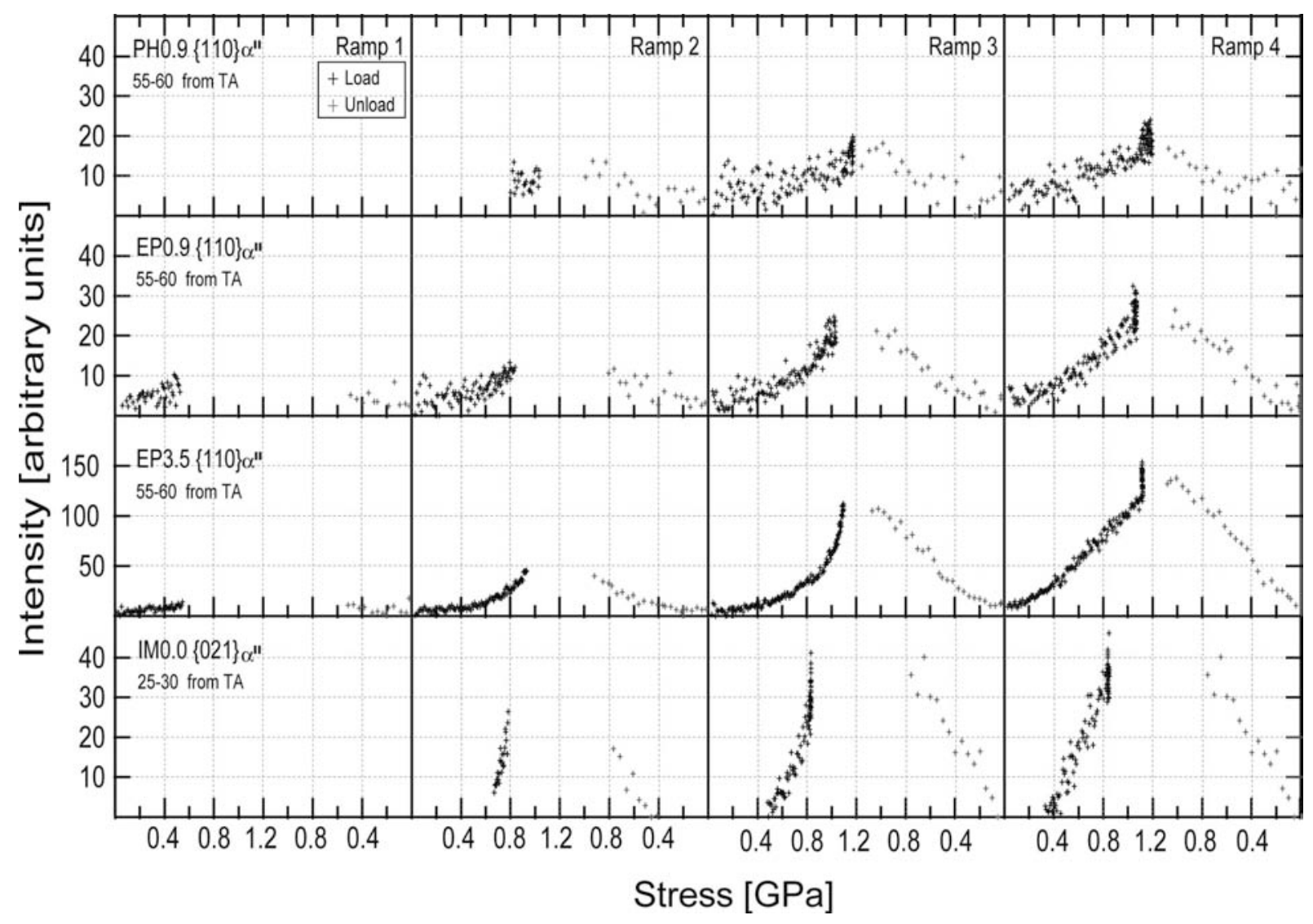

Figure 8: Change in intensity of the $\{110\}_{\alpha^{\prime \prime}}$ or $\{021\}_{\alpha^{\prime \prime}}$ peak with stress during cyclic loading (Figure 5) of the PH0.9, EP0.9, EP3.5 and IM0.0 specimens. For each specimen the diffraction rings were binned at the labelled $5^{\circ}$ segment from the tensile axis (TA). 


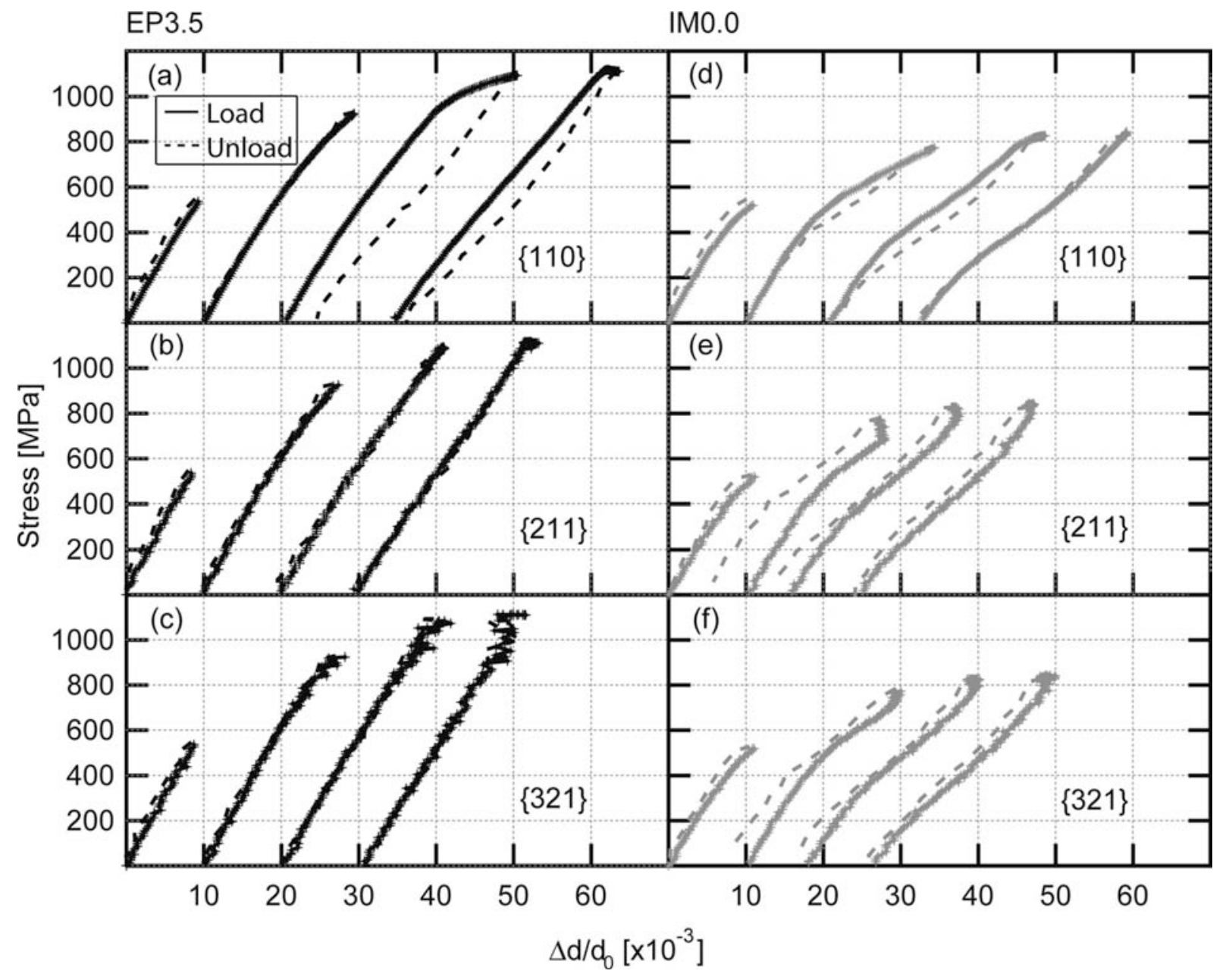

Figure 9: Stress - lattice strain curves from $\{110\},\{211\}$ and $\{321\}$ during the loading - unloading tests in 6: (a) - (c) EP3.5 and (d) - (f) IM0.0. This data is taken from a 10 degree region from grains with plane normals parallel to the tensile direction. Each loading step is offset by $1 \times 10^{-2}$ on the lattice strain axis. 

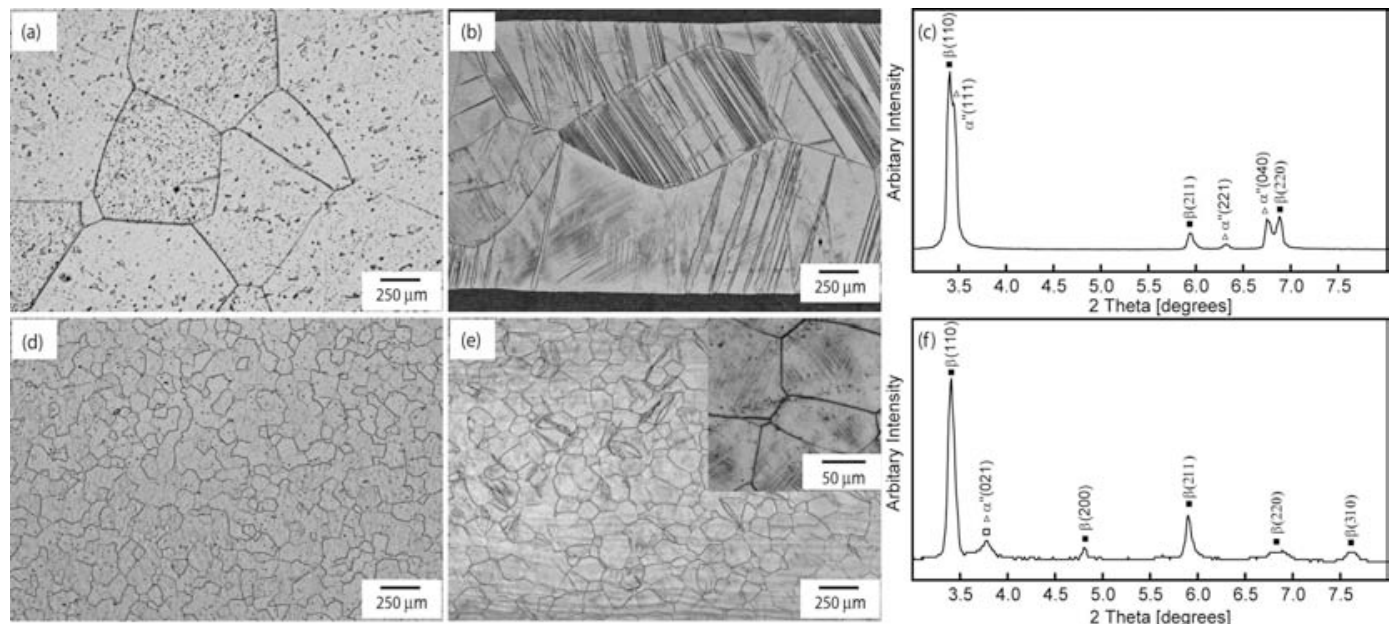

Figure 10: (a-c) Change in microstructure of Ti-29Nb-13Ta-4.6Zr; (a) light micrograph before deformation, (b) after $8 \%$ strain, (c) in-situ XRD profile at 5\% nominal strain from a $10^{\circ}$ segment of the diffraction pattern, $25^{\circ}$ from the tensile axis; (d-f) Change in microstructure of EP0.0, (d) light micrograph before deformation, (e) after failure; inset: microstructure at a higher magnification. (f) insitu XRD profile at $15 \%$ nominal strain from a $10^{\circ}$ segment of the diffraction pattern, $25^{\circ}$ from the tensile axis 


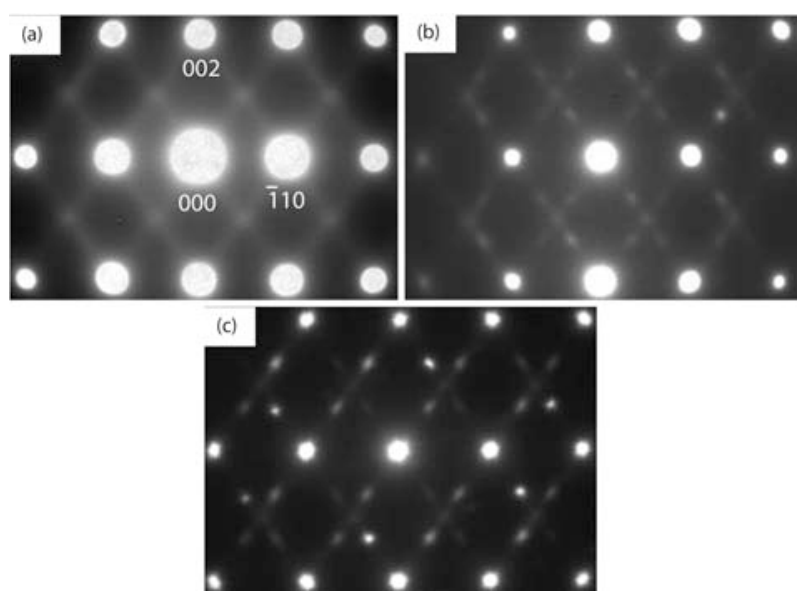

Figure 11: Diffraction Pattern from (a) EP0.0, (b) EP0.9 and (c) IM0.0. Beam direction is close to $[110]_{\beta}$. 


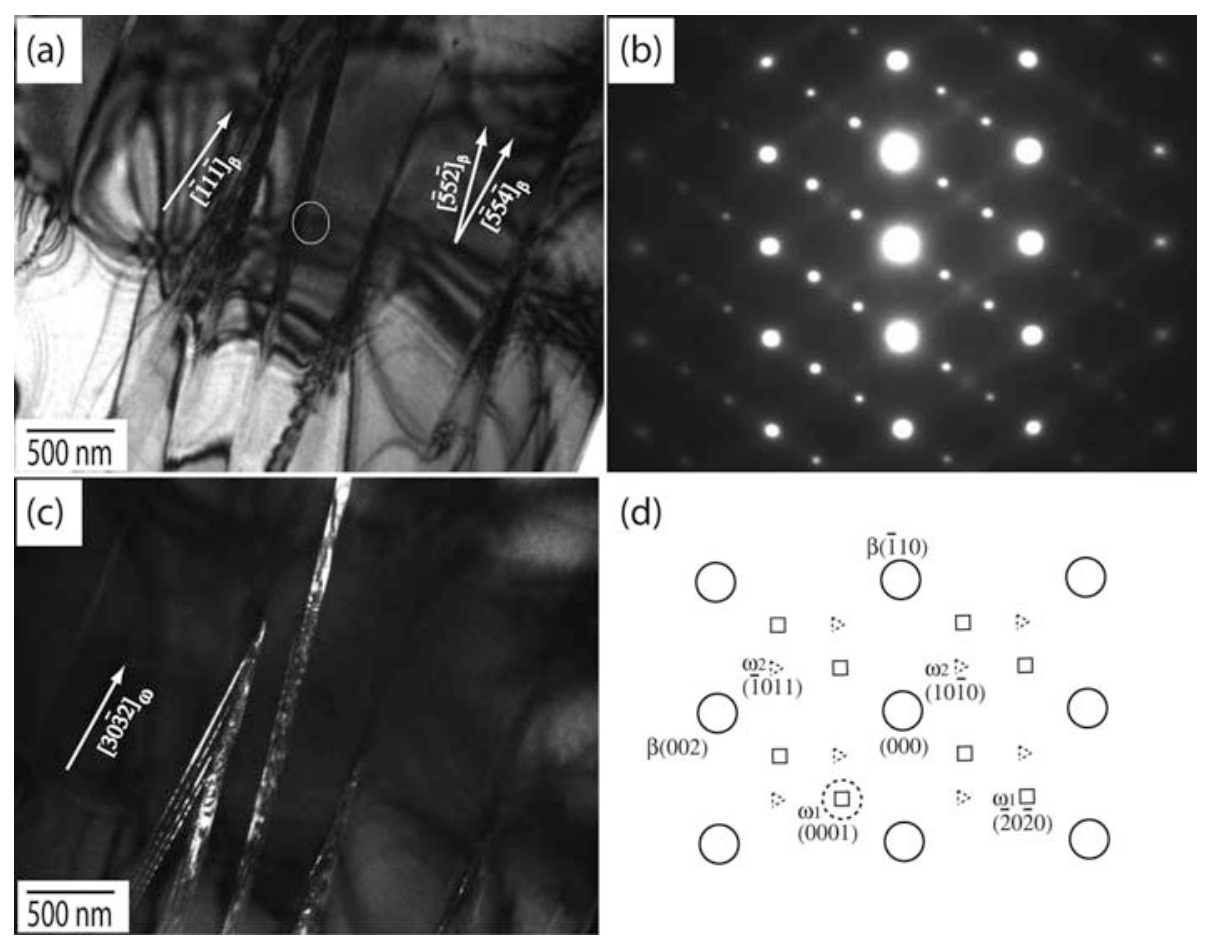

Figure 12: (a) TEM bright field image and (b) corresponding $[110]_{\beta}$ zone SAD pattern of highlighted region in (a) from the EP0.0 specimen; (c) dark field image; (d) key diagram for SAD pattern in (b); The dark field image in (c) was taken using the $(0001)_{\omega 1}$ reflection highlighted in (d). 


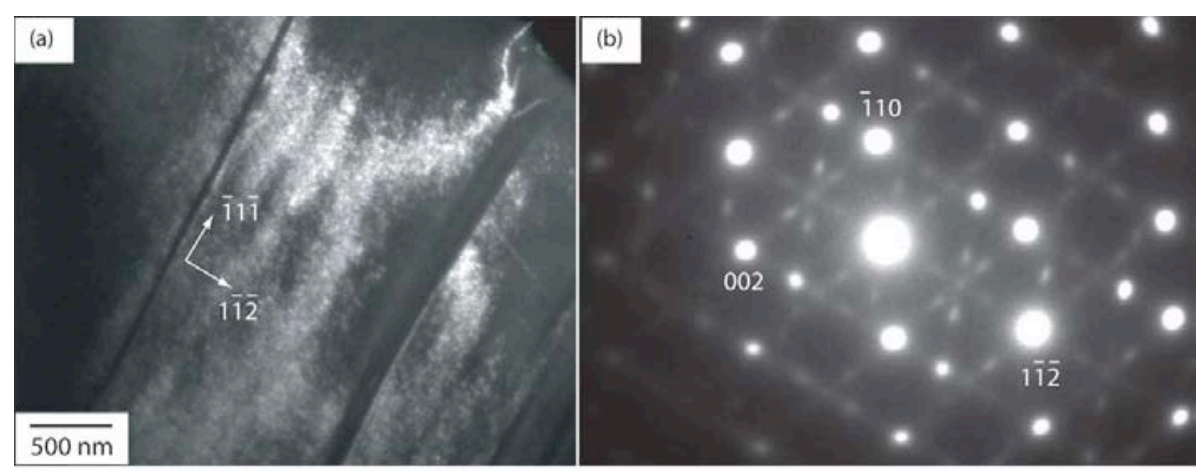

(c)

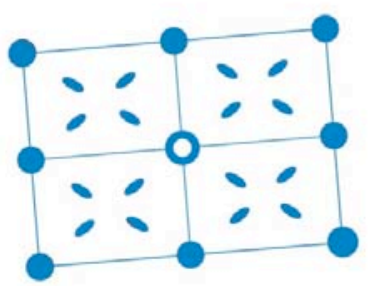

bcc Matrix (d)

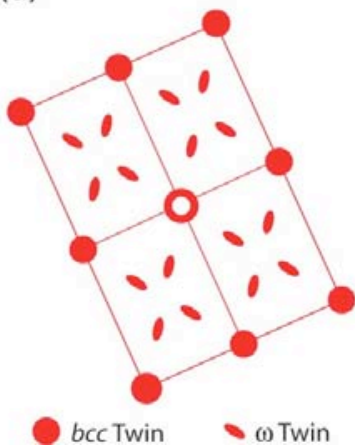

(e)

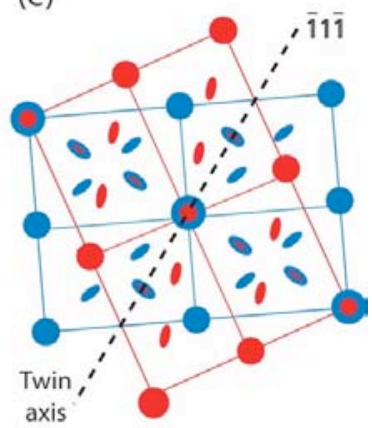

Figure 13: (a) TEM dark field image showing $\{112\}<111>$ twins in the EP0.9 specimen; (b) SAD pattern of area in (a); (c)-(e) key diagrams of (b) showing; (c) diffraction pattern from matrix; (d) diffraction pattern from twin; (e) compilation of (c) and (d). The beam direction is close to [110 $]_{\beta}$. 


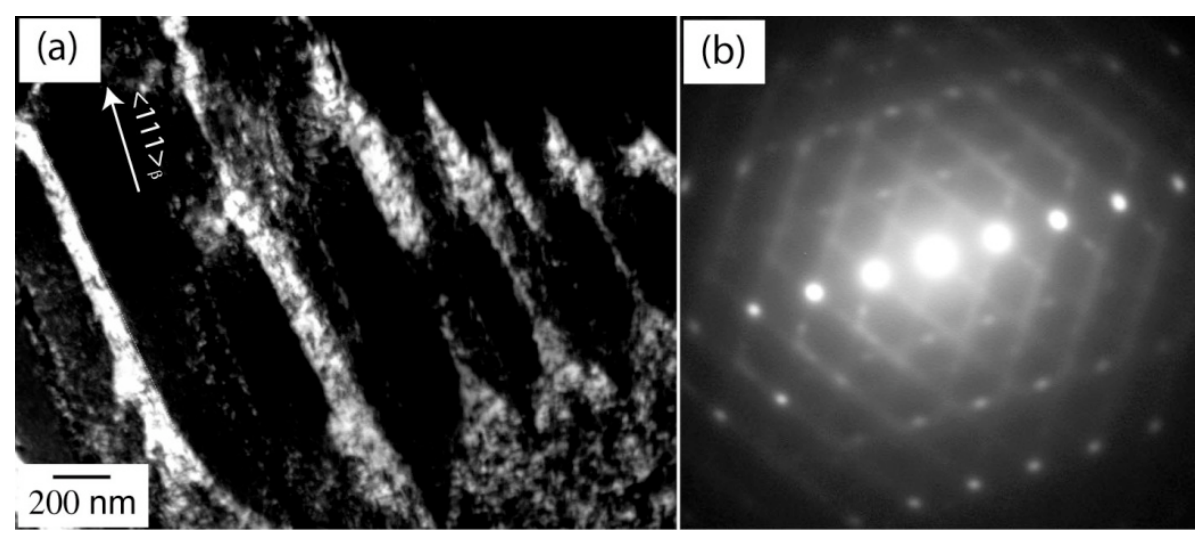

Figure 14: (a) Dark field TEM image showing stress-induced $\omega$ plates in the IM0.0 specimen; (b) $\mathrm{SAD}$ pattern of area in (a) with zone axis close to $[\overline{1} \overline{1} 2]_{\hat{a}}$. 


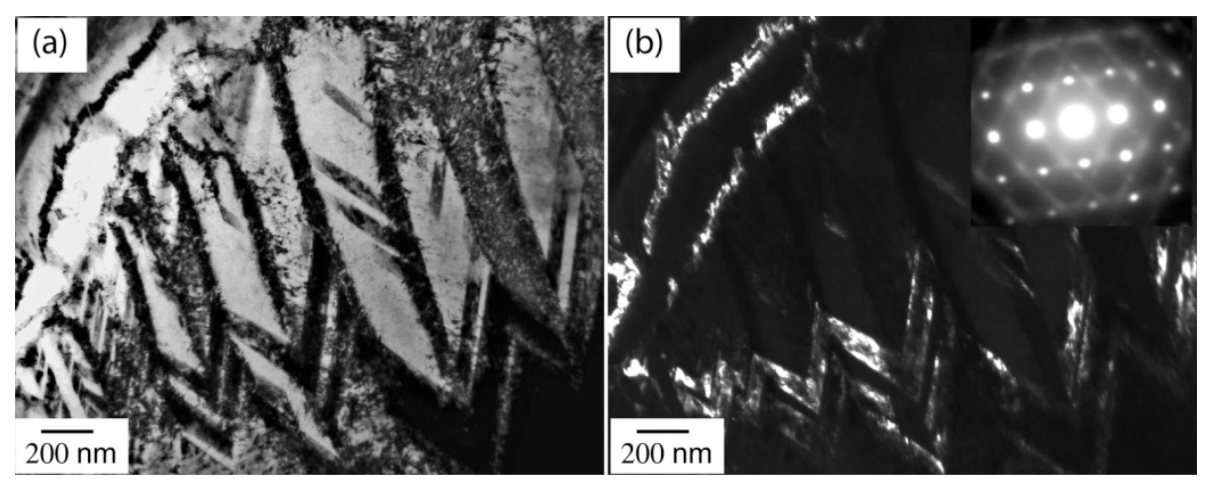

Figure 15: (a) Bright field TEM image from the same area as in Figure 5.13 in the IM0.0 specimen, and; (b) corresponding dark field image of the same area as (a); inset [001 $]_{\beta}$ SAD pattern. 


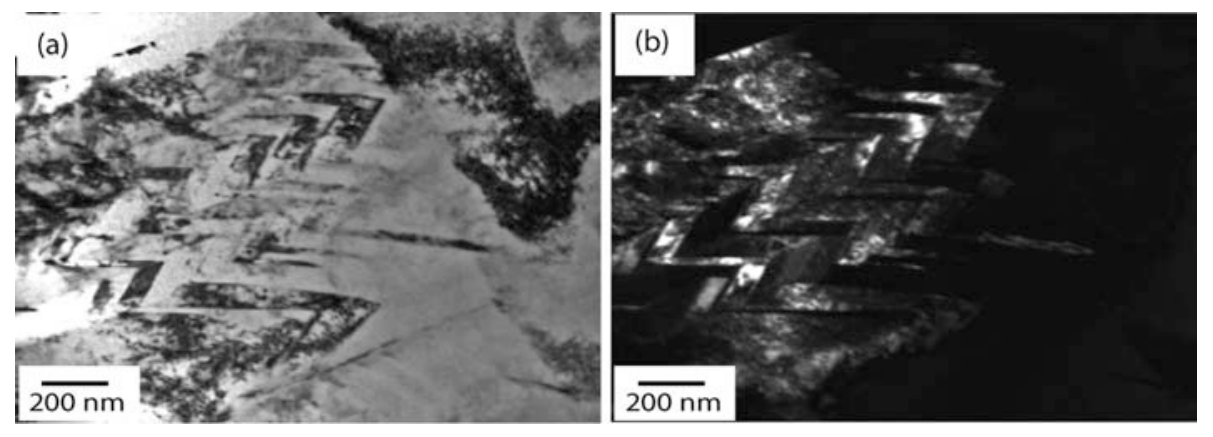

Figure 16: (a) TEM bright field image and (b) corresponding dark field image showing faults in the IM0.0 specimen. 


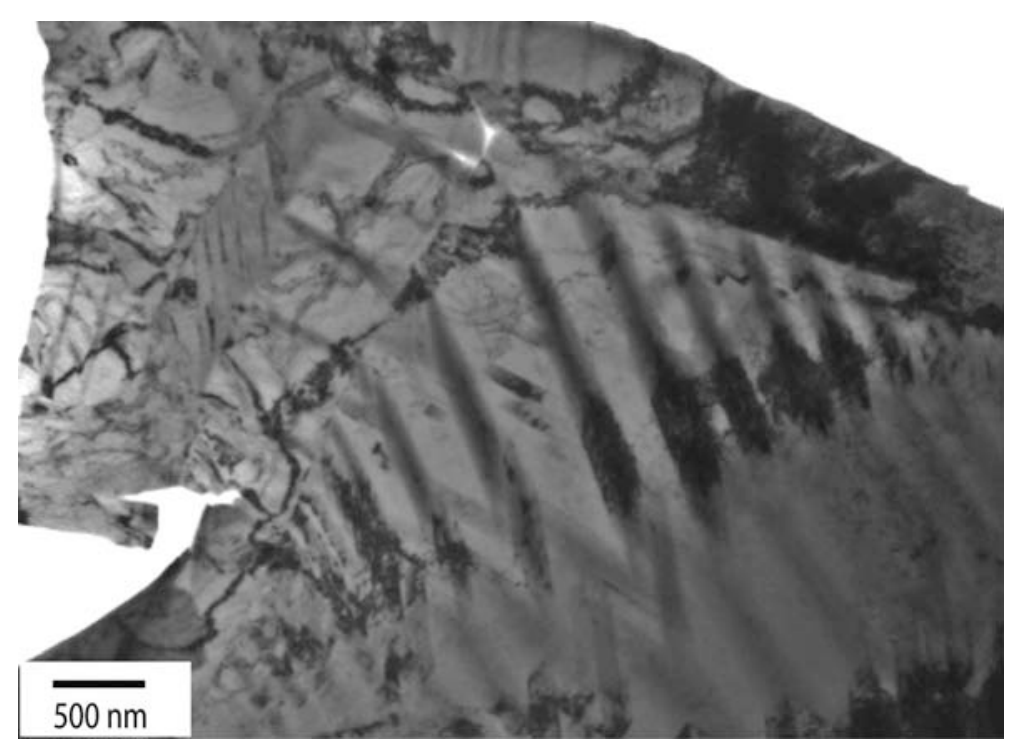

Figure 17: TEM bright field image showing step-like features in the IM0.0 specimen. 

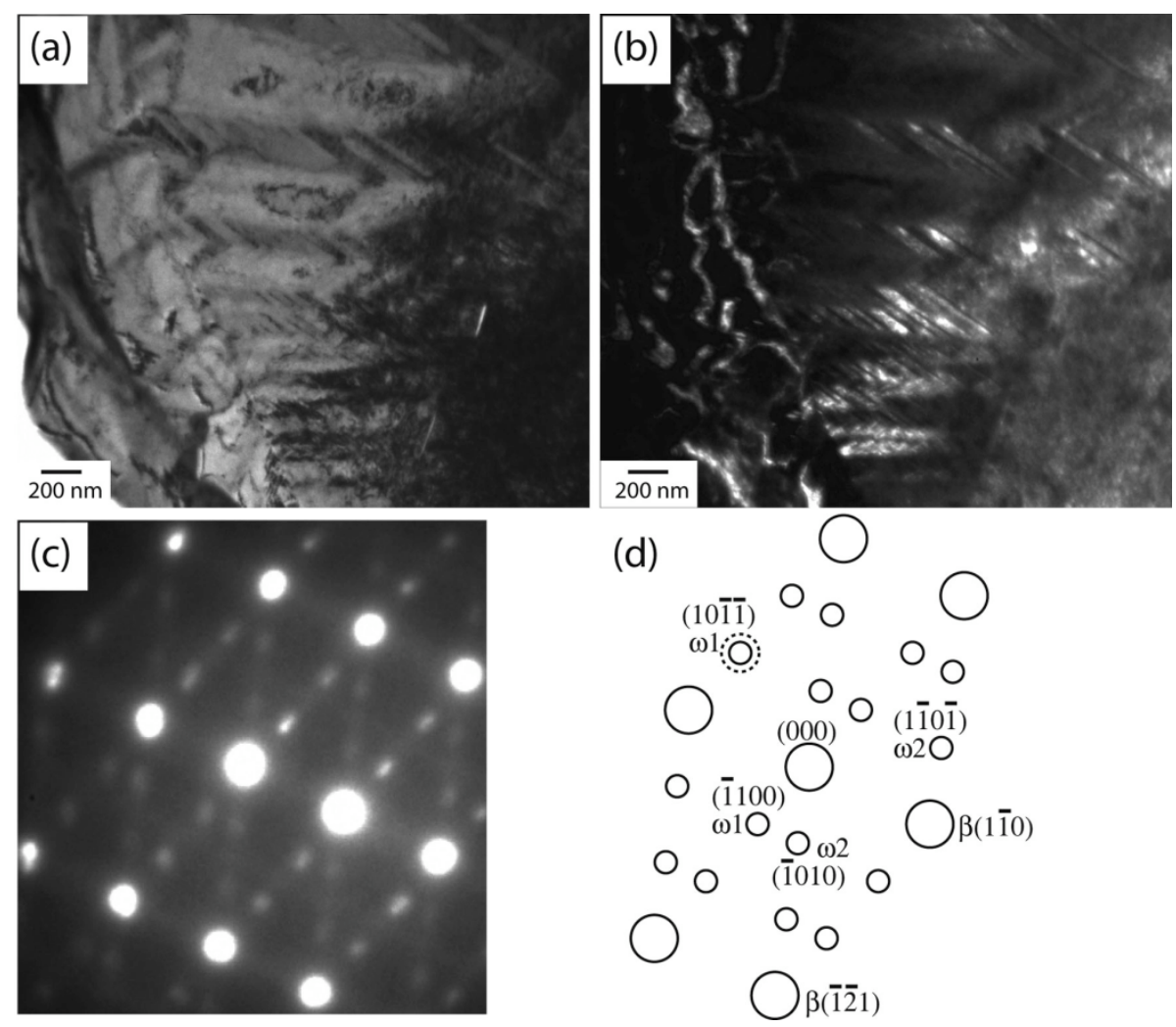

(d)

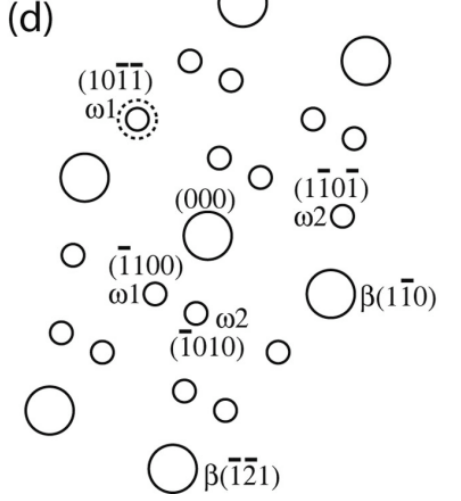

Figure 18: (a) Bright field and (b) corresponding dark field image of the steps from Figure 5.16, one of the fault planes is composed of one variant of $\omega_{\text {ath }}$ plates; (c) [113 $]_{\beta}$ zone SAD pattern of the same area. The dark field image in (b) is obtained from the $(10 \overline{1} \overline{1})_{\dot{u}}$ spot; (d) key diagram for SAD pattern in (c). 

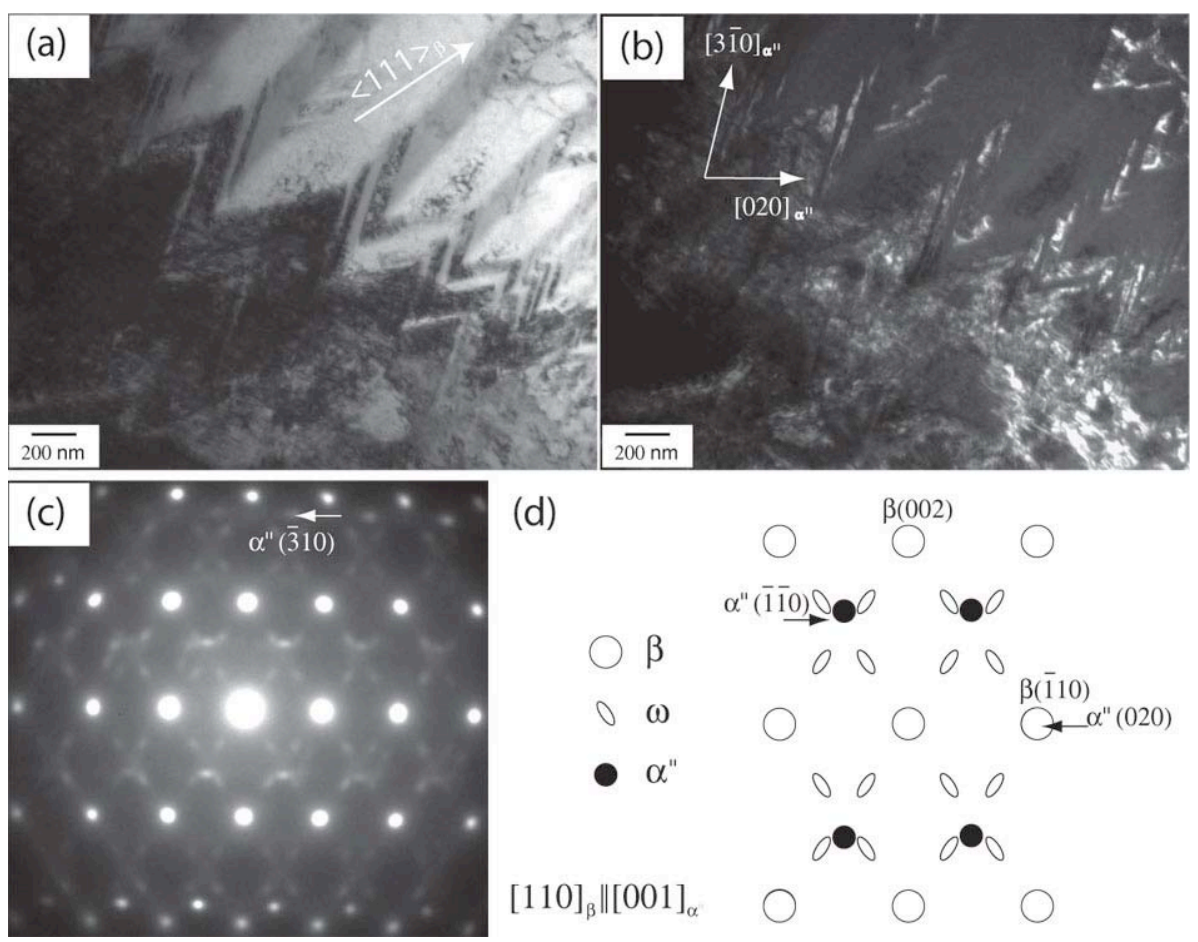

Figure 19: (a) TEM bright field and; (b) dark field image of the same area in (a) from the IM0.0 specimen; (c) SAD pattern with the beam direction close to $[110]_{\beta}$; (d) key diagram of (c). The dark field image in (b) is obtained using the ( $\overline{1} \overline{1} 0)$ á" spot. 


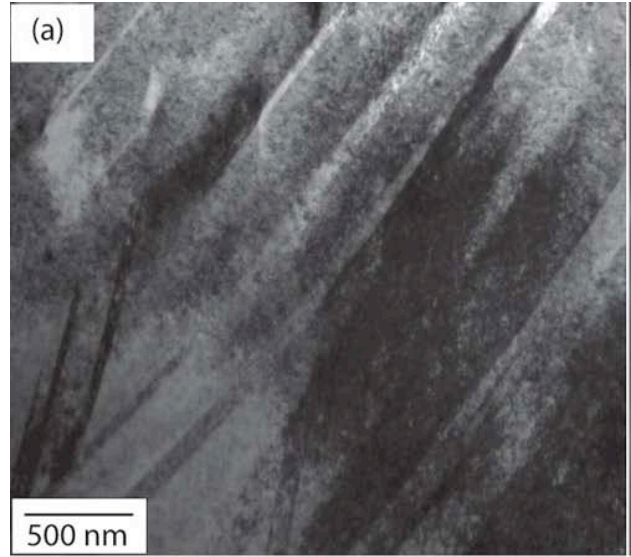

(c)

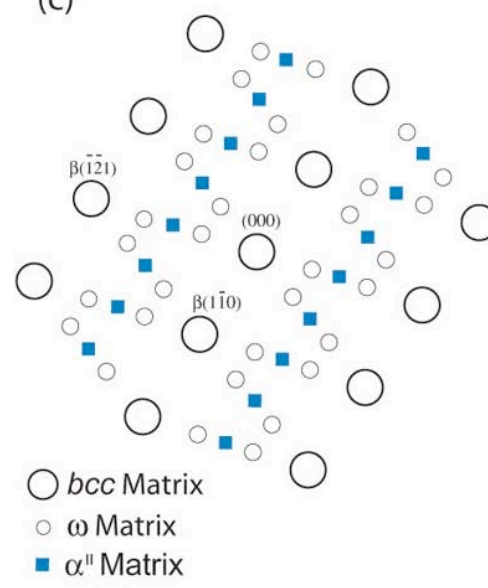

(d)

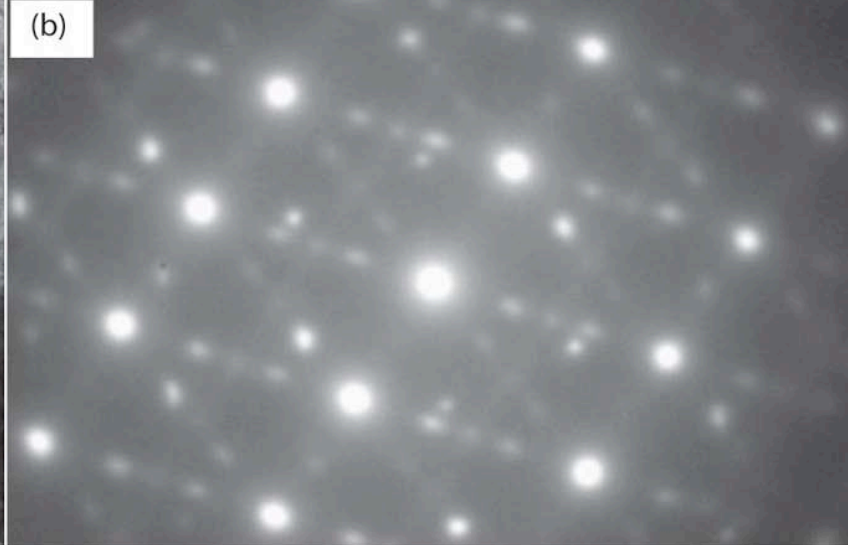

(e)

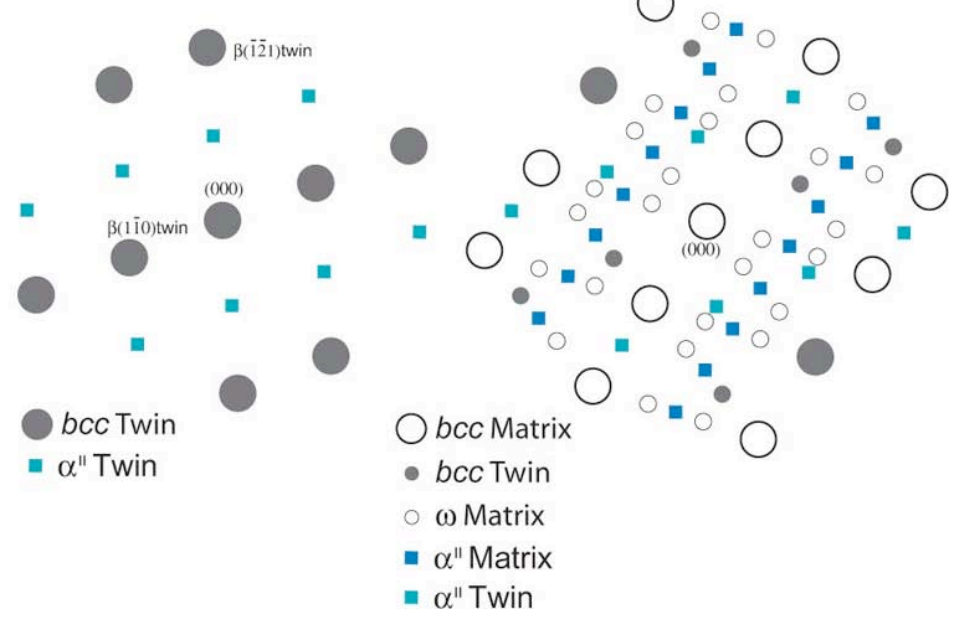

Figure 20: Twinned area from the EP0.9 specimen; (a) bright field image; (b) SAD pattern from (a) with beam direction close to [113 $]_{\beta} ;$ (c) - (e) key diagrams of diffraction pattern in (b) showing that it is composed of (c) $\beta$ matrix, with reflections from both $\omega$ and $\alpha^{\prime \prime}$; (d) twinned $b c c$ reflections, with reflections from one $\alpha$ " variant; (e) compilation of (c) and (d). 
(a)

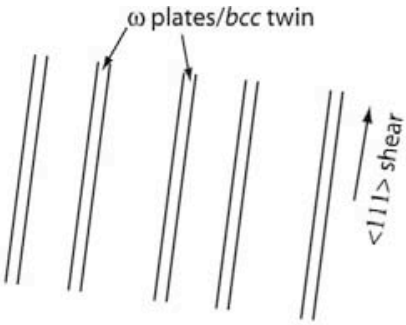

(b)

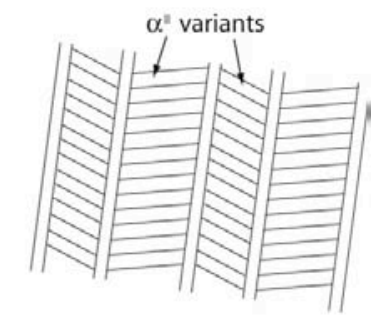

(c)

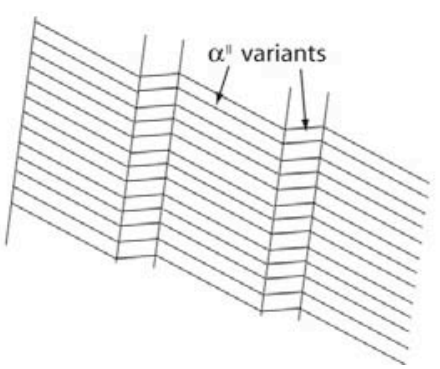

Figure 21: Schematic diagrams showing the formation of the faults observed in Gum metal; (a) formation of stress-induced $\omega$ plates or $b c c$ twins formed after quenching or working (e.g .cold rolling); (b) formation of $\alpha^{\prime \prime}$ during deformation from the interface of the $\omega$ plates or twins; (c) strain accommodation of $\alpha$ " variants during further deformation. 